Mónica Silva Contreras
Arquitecta Doctora, Universidad Central de Venezuela. Profesora en la Universidad Iberoamericana, Ciudad de México.

\title{
Arquitectos y contratistas modernos en México \\ Vínculos internacionales entre De Lemos \& Cordes y Milliken Brothers, 1898-1910
}

\author{
Keywords: Gonzalo Garita, Adamo Boari, Casa Boker, La Mutua, Palacio de Correos, \\ Siegel-Cooper \& Co., R. H. Macy \& Co
}

It is known that during the first decade of the twentieth century in Mexico was built a large number of buildings, both public and private, which meant the dissemination of modern building materials and techniques. Many of them were the results from new construction management processes, since their implementation implied the importation of complex and large structures which included different materials. More than about their technical-constructive aspects, this article seeks to emphasize the incorporation of the management mechanisms that these implied.

The projects of the architects Theodore De Lemos and August Cordes, built by Mexican engineer Gonzalo Garita, with Edward and Foster Milliken's steel structures company, also based in New York, were the result of the development of a market in which appeared the first entrepreneurs of modern construction in the country. The work focuses on the realization in Mexico City of the buildings for Casa Boker and for the Mutual Insurance Company of New York, in the context of the works of the designers and contractors in Manhattan, Cape Town or Johannesburg. In this way we understand a modern management of projects and works in advance of our day's globalization.

$E^{1}$ objetivo de este artículo se centra en el desentrañamiento de las relaciones que, entre los Estados Unidos y México, tuvo la firma de arquitectos liderada por Theodore W.E. De Lemos (1850-1909) y Auguste W. Cordes (1850-¿?) con la empresa constructora de los hermanos Edward F. (1862-1906) y Foster Milliken (1863-1945). ${ }^{1}$ Dichas conexiones dejan ver sus realizaciones en la capital mexicana como parte de su producción internacional de edificios modernos, particularmente en el contexto de la historia de los edificios comerciales y primeros rascacielos en Chicago y Nueva York.

El trabajo se inserta en la investigación acerca de las redes profesionales y empresariales, nacionales e internacionales, que se entretejieron con las relaciones entre proyectistas y constructores, asi como de comitentes, durante la primera década del siglo XX. Dichas relaciones fueron claves para la realización de edificios que forman parte importante del imaginario de la primera modernización de México en su ciudad capital.

Entre los temas de mayor interés en la historiografia de la arquitectura de los primeros años siglo XX en México han estado algunos edificios con funciones comerciales de indudable impacto, tales como la primera sede de El Palacio de Hierro en la Ciudad de
México o el edificio de Las Fábricas de Francia en Puebla. El contexto de los barcelonettes en el desarrollo de las primeras tiendas de ropa y accesorios de moda franceses ha sido ampliamente estudiado como eje de una cultura de consumo (Martínez 2005; Gamboa 2013). La misma que ha llevado tradicionalmente a considerar, a partir del prestigio de ciertos proveedores de bienes de consumo cotidianos, un predominio francés indiscutible en el imaginario de la capital de 1880 a 1910.

Sin embargo, al revisar las relaciones comerciales de México entre 1900 y 1910 es posible advertir que estas involucraban un porcentaje mucho mayor de operaciones con los Estados Unidos, con Inglaterra y con Alemania que con Francia. ${ }^{2}$ La idea de una época "afrancesada" da paso, entonces, a la imagen de un abanico de referencias mucho mayor en esos años. En tal contexto, las influencias comerciales significaron presencia cultural diversa mediante revistas, prensa diaria y vida social, no sólo en francés sino en inglés y alemán, del mismo modo que ocurría en otras capitales latinoamericanas. ${ }^{3}$

Equipamiento técnico para la minería y la agricultura, elementos para infraestructura territorial y mobiliario urbano, así como materiales y sistemas constructivos, llegaron a México desde finales del siglo XIX mediante 
la compra directa a fabricantes o a través de agentes importadores de diversas nacionalidades establecidos en el país desde países distintos a Francia. De hecho, las estructuras metálicas, construidas a partir de 1850 y con su mayor auge en la última década del siglo, tienen orígenes diversos que acusan tanto a proveedores europeos como estadounidenses (Vassallo 2013: 1043-1045).

De modo similar, las marcas de cemento más tempranamente disponibles en México fueron británicas. Luego las hubo alemanas, belgas, danesas, norteamericanas y mexicanas, pero no hay datos de marcas francesas entre las más de treinta que se comercializaron entre 1900 y $1910 .{ }^{4}$

Los edificios más relevantes de este trabajo involucran constructores y materiales de origen estadounidense junto a profesionales como Gonzalo Garita, ingeniero mexicano, o el italiano Adamo Boari, quienes trabajaron en ese contexto de proyectos y contratos internacionales. El resultado fue la construcción de edificios como la Casa Boker, la sede del servicio postal mexicano - conocido como Palacio de Correos - y el edificio de la Mutual Insurance Company. En esos tres ejemplos confluyó el trabajo de la firma de arquitectos De Lemos \& Cordes con la fabricante de estructuras de acero Milliken Brothers. Esta última participaria seria responsable de otras edificaciones protagonistas de la primera modernización de la arquitectura mexicana, aquella resultante de la actualización en materiales, técnicas y gestión de obras.

En estas páginas se presenta, entonces, una cara de la modernidad constructiva que establece parentescos formales y técnicos entre la arquitectura de lugares del mundo muy distantes entre sí. Distintos tipos estructurales y funcionales, como los edificios comerciales y de oficinas, se afianzaban internacionalmente y resulta oportuno esbozar ese panorama con ejemplos en Nueva York, Ciudad de Cabo o Johannesburgo, del mismo modo que en la Ciudad de México.

La historiografia de la arquitectura ha establecido paradigmas que han desplazado a un segundo plano, cuando no ignorado, casos que mediante formas, funciones, nacionalidad de sus componentes o fabricantes, muestran lo que entonces no se conocía como globalización y que hoy no dudaríamos en llamar así. Los constructores mexicanos participaban de aquel proceso, con lo cual resulta importante insertarlos en el mismo para entender diversas coincidencias que explican una modernización difícil de entender en su complejidad asilando los casos locales o entendiendo los internacionales como antecedentes, cuando fueron contemporáneos a lo realizado en México.

\section{Nuevos tipos arquitectónicos: Edificios de oficinas con equipamiento moderno}

Cuando se anunciaba su pronta terminación, el edificio para El Centro Mercantil (1896-1897) fue reportado como el primero con funciones mixtas, es decir, comercio y oficinas, en la Ciudad de México. Con se inauguraba en la capital “...un útil género de construcciones, de las cuales esta sería el primer modelo, pues hasta ahora nos habian sido desconocidas..." (S.A., El mundo ilustrado, 1898: 474). El funcionamiento de este "ensayo", como se le calificaba, dependía de la energía eléctrica y su moderno equipamiento

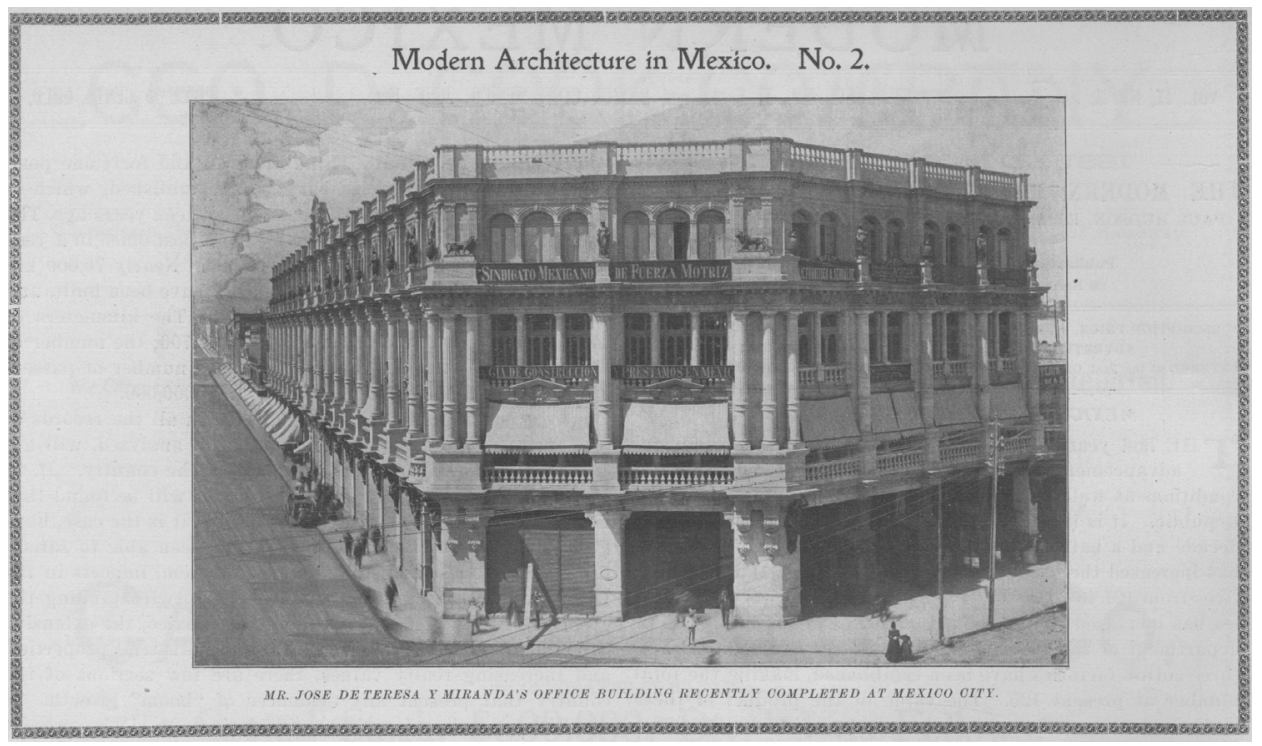

Figura 1. Centro Mercantil, Ciudad de México. Arquitectura Daniel Garza, construcción Gonzalo Garita, 1896-1898 Esquina Zócalo y calle 16 de septiembre. "Modern Architecture in Mexico $N^{\circ}$ 2". Modern Mexico, vol. IX, num. 9, junio 1900, p. 6. 


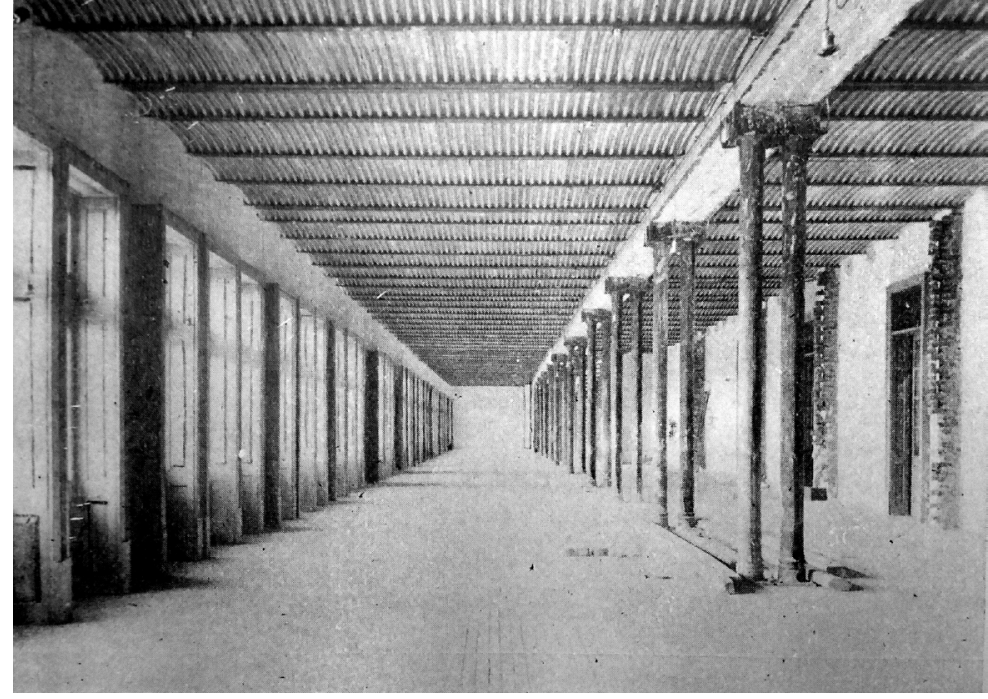

Figura 2. Centro Mercantil, Ciudad de México. Arquitectura Daniel Garza, construcción Gonzalo Garita, 1896-1898 Departamento al interior del edificio sin dividir. "México moderno: el Centro Mercantil", El mundo ilustrado, diciembre 25 de 1898 , p. 476 fue central en su promoción. En el reporte citado se describía la planta eléctrica del edificio como "la última perfección conocida en el género". La falta de un servicio público de electricidad regular en la ciudad se evidencia en la nota cuando refiere "una excelente batería de acumuladores que dan luz y fuerza durante el tiempo que no trabaja el motor de vapor" (S.A., El mundo ilustrado, 1898:474). La descripción del elevador y sus horarios de funcionamiento, asi como del "empleado especial con lujosa librea para manejarlo", dejan ver que no era éste un artefacto usado en la capital (S.A., El mundo ilustrado, 1898:474). Se trataba de una reciente apropiación de los edificios de oficinas estadounidenses.

El Centro Mercantil (figura 1) contaba con 23 locales comerciales, ofrecía 100 para oficinas, para las cuales tenía agua corriente en los baños de cada piso, buzones de correo, estación telegráfica y telefónica (Figueroa 1899: 96). El moderno y lujoso edificio era obra de Daniel Garza (1865-1926) y su construcción en el débil suelo de la Ciudad de México, por lo cual destacaba la cimentación del edificio, estuvo a cargo del ingeniero Gonzalo Garita (1867-1921).

Las posibilidades técnico-constructivas abrian la opción de la planta libre en este edificio cuyos muros carecian de compromiso estructural:

El interior del edificio está subdividido en lotes cuya unidad de medida son 5 metros de frente por 8 de fondo... Es fácil remover las divisiones entre los lotes, de maneras que si alguien necesitare dos o más lotes en extensión, pero formando un solo cuarto o bien subdividido en varias piezas, puede obtenerlo. (S.A., El mundo ilustrado, 1898:474).
El módulo para la distribución de los locales correspondería a la ubicación de las columnas metálicas y según el gusto de cada usuario habria la opción de plafones para cubrir las bóvedas metálicas acanaladas (figura 2).

El edificio se ubica en una de las esquinas del Zócalo capitalino, por lo cual en la cara que da hacia la plaza ofrece continuidad a los portales y acceso por la fachada más larga, hacia la calle hoy llamada 16 de septiembre. Una descripción, recién abierto el edificio, planteaba: "en el frontis principal, a cada lado, hay estatuas de bronce, fundidas por T. Caradente, que representan la Industria y el Comercio. Sobre ellas, en el segundo cuerpo, dos leones parecen proteger la entrada del edificio". ${ }^{5} \mathrm{El}$ carácter del edificio para su vocación se hacía patente con las esculturas añadidas. $^{6}$

Con el trabajo conjunto de Garza y Garita se abría el capítulo de los modernos edificios de oficinas en la Ciudad de México. El eclecticismo de su fachada ocultaba una moderna estructura con moderno equipamiento. ${ }^{7}$

\section{La llegada de una firma de arquitectos de Nueva York a la Ciudad de México}

Otro edificio que en la capital mexicana conjugaria la función comercial con la de oficinas, esta vez las de la propia firma, sería el de Roberto Boker y Cía. (1898-1900). La llegada de Boker a la capital mexicana en 1865, después de una temporada neoyorkina, formaba parte de la estrategia comercial de la familia prusiana con origen en Reimscheid, al noreste de Colonia. Luego de varios años, la firma comercial buscaba su presencia definitiva en la Ciudad de México con la construcción de un edificio emblema que la situara en el imaginario colectivo.

Tal vez por recomendación de los primos instalados en Nueva York, los propietarios de la Casa Boker en México apuntarían hacia dos arquitectos también de origen alemán. ${ }^{8}$ Theodore Wilhelm Emile De Lemos, nacido en Holstein y educado en la Bauakademie de Berlin, y August Wilhelm Cordes, originario de Hamburgo y formado en Berlin y Viena, eran socios desde 1884. Buena parte de sus proyectos y obras fueron para germano parlantes emigrados a Nueva York o para sociedades ligadas a los mismos. ${ }^{9}$ De hecho, el primer edificio conocido de los arquitectos fuera la desaparecida sede de la Arion Society, 1885-87, la cual organizaba conciertos de música clásica y canto coral, con preminencia de autores y figuras alemanas. El edificio 


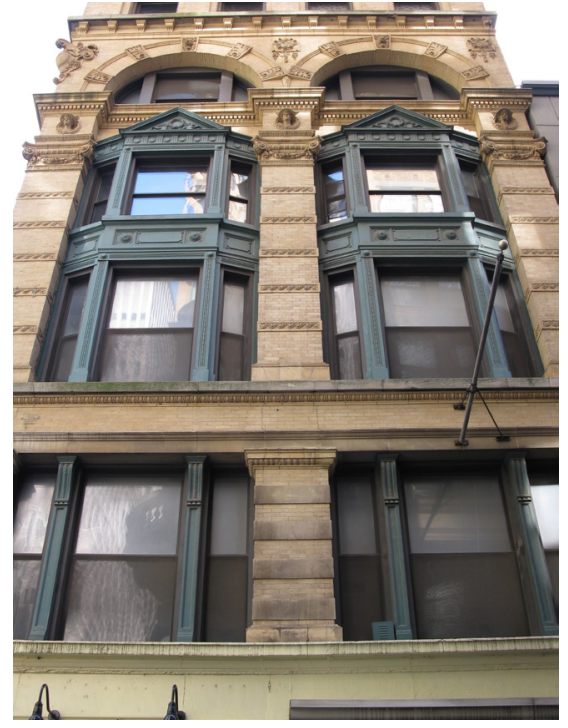

presentaba la configuración que caracterizaría a los edificios de la firma, diferenciando sus tres niveles a modo de palazzo renacentista (Miller 2012).

Los primeros edificios de oficinas de estos arquitectos alemanes coincidieron con la inserción de las estructuras de esqueleto metálico, las cuales abrian la posibilidad de construir incipientes rascacielos en Nueva York, un poco más tarde que los pioneros en Chicago. ${ }^{10}$ Destacan cinco edificios, con poca variación en los materiales de sus fachadas, diferenciación de la planta baja, del primer nivel y los siguientes, así como énfasis en el último nivel, con una gran cornisa que cierra el desarrollo del inmueble en altura. Poco conocida la relación entre ellos, adquieren sentido como parte de esta historia internacional de arquitectos y contratistas, el Eimer \&

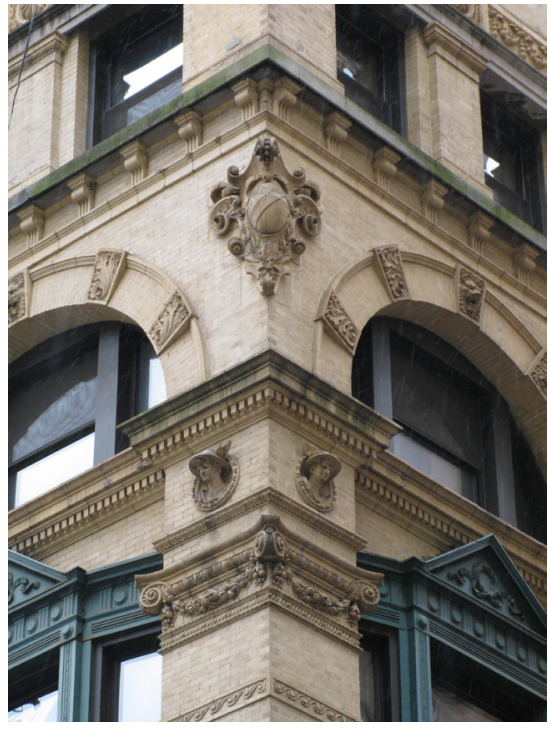

Amend Building, construido en 1886 para Bernard Amend y Carl Eimer, químicos alemanes nacidos en Darmstadt y establecidos en New York como importadores de medicinas y productos químicos (Langlois 2012); el edificio para Edwin C. Burt and Co., construido en 1888 (St. Croix Architecture); el edificio de Armeny \& Marion (figuras 3 y 4), terminado en 1890 (Miller 2012); el Fulton Building (figura 5) de 1897 (Miller 2012); y el edificio construido en 1897 para la tienda y la fábrica de Henry Heide, empresario nacido en Obermarsberg, Westphalia (Grutchfield 2009; St. Croix Architecture). El edificio más alto por De Lemos \& Cordes en ese contexto fue construido entre 1892-1893 para los también alemanes William Keuffel y Hermann Esser, quienes encabezaban la firma Keuffel \& Esser Co (figura 6). (NYC Landmarks Preserva-
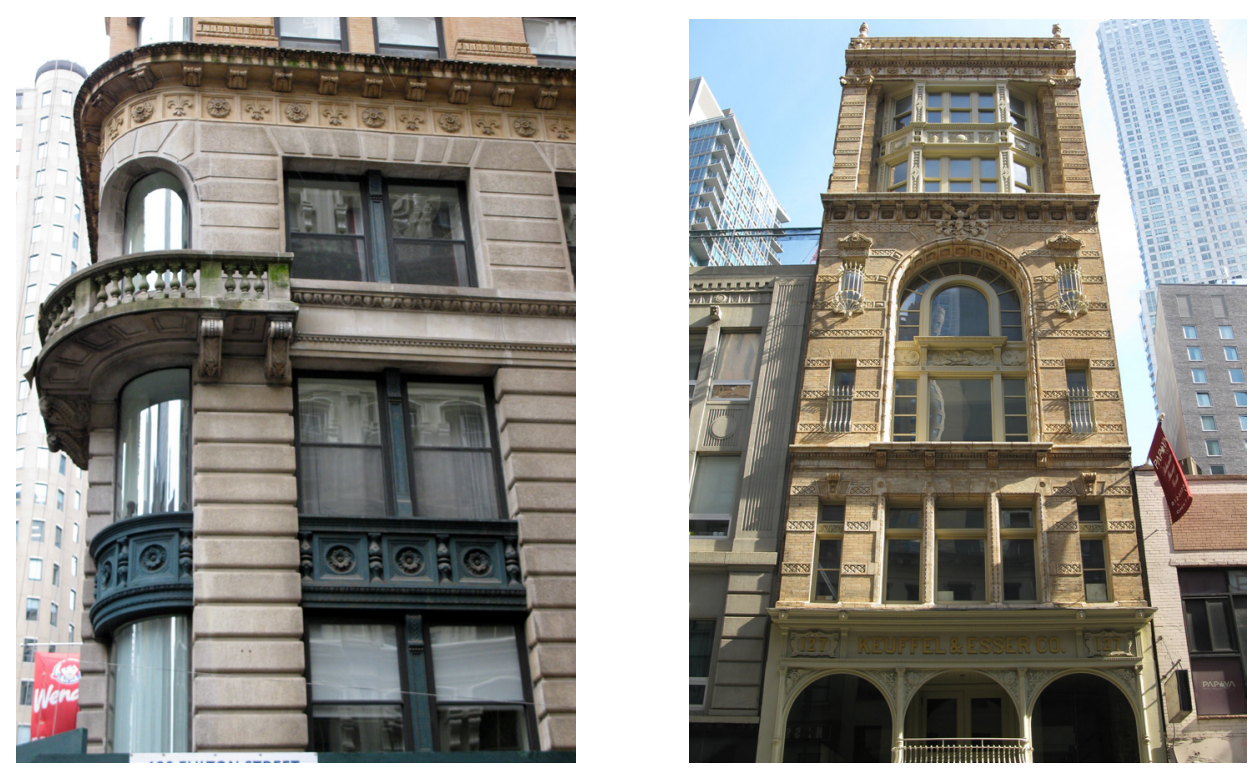

Figuras 3 y 4. Armeny \& Marion Building, 124 Fulton Street, New York. De Lemos \& Cordes, 1888-1890. (3) Fachada hacia Nassau Street. Foto: Mónica Silva, 2014. (4) Detalle de la esquina. Foto: Mónica Silva, 2014.
Figura 5. Fulton Building, 87 Nassau Street, New York. De Lemos \& Cordes, 1897. Foto: Mónica Silva, 2014.

Figura 6. Keuffel \& Esser Co. Building, 127 Fulton Street, New York. De Lemos \& Cordes, 1892-1893. Foto: Mónica Silva, 2014. 
Figuras 7 y 8. Siegel Cooper Department Store. Arquitectura De Lemos \& Cordes, construcción Milliken Brothers, 1896. (7) Detalle de la fachada hacia West 18th St. Foto: Mónica Silva, 2014. (8) Acceso desde Sixth Avenue. Foto: Mónica Silva, 2014

Figuras 9 y 10. Edificio de Roberto Boker y Cía., 16 de Septiembre e Isabel La Católica, Ciudad de México. Arquitectura De Lemos \& Cordes, construcción Milliken Brothers - Gonzalo Garita, 1898-1900. (9) Perspectiva con firma. Foto en aviso comercial en J. Figueroa Domenech. Guía general descriptiva de la República Mexicana, México, Ramón de S.N. Araluce, 1899, Vol. 1, p. s/n. (10) Edificio en construcción. Milliken Brothers Catalogue: Second Export Edition. 1905. New York, 1905, p. 139 .
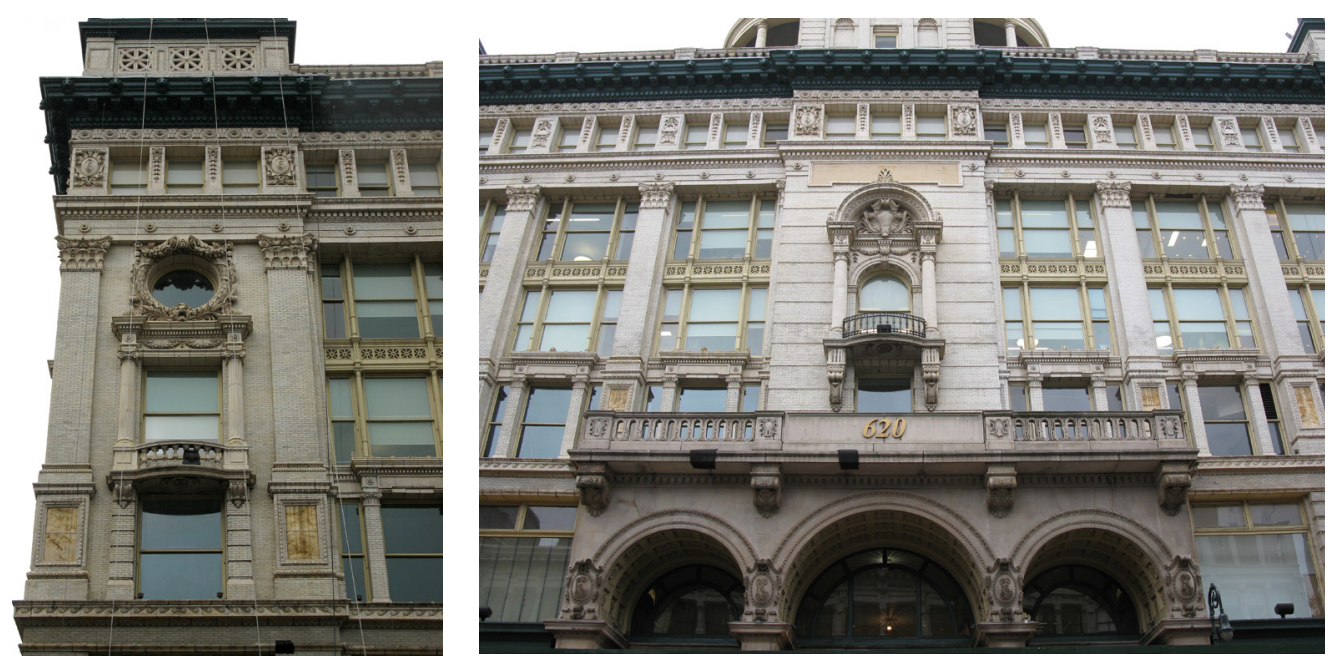

tion Commission 2005). La separación de las fachadas en varias partes con uno, dos o tres pisos, seguramente buscó proporcionar secciones, y sólo diferenciar funciones. ${ }^{11}$

La compañía establecida en 1887 por Henry Siegel, Frank H. Cooper e Isaac Keim en Chicago, estrenó en 1896 el edificio Siegel-Cooper \& Co. Department Store (figuras 7 y 8) en Nueva York como parte de la estrategia comercial de expansión empresarial. El edificio ocupó, en su momento, el segundo lugar entre los más costosos construidos de la ciudad, pues varios de los contratos para elevadores, elementos de fundición e instalación eléctrica estuvieron entre los mayores de su tiempo. La primera gran tienda por departamentos construida con sistema porticado metálico en la ciudad, obra de los constructores Edward y Foster Milliken, fue promocionada como la única completamente a prueba de incendios y fue el referente más importante para la construcción y gerencia de su tipo en esos años (NYC Landmarks Preservation Commission 1989).

Los administradores de la Casa Boker tenían, entonces, al más prestigioso y notable edificio de su género como modelo para la construcción del suyo en la ciudad de México. En el mismo se reunieron la formación en la tradición académica internacional de los arquitectos de esas décadas, con las consideraciones que para entones se abrían a las nuevas funciones y posibilidades técnicas (figuras 9,10 y 11).

Al estar ubicado en una esquina, el ingreso a la tienda ocurre desde esta, con acceso separado hacia las oficinas. Predomina en la sección pública del edificio el partido arquitectónico característico de las grandes tiendas departamentales, con patio central cubierto con una estructura metálica cerrada con vidrio y escalera en el eje del mismo. La cantería de la fachada, de procedencia local, presenta almohadillado rústico en la planta
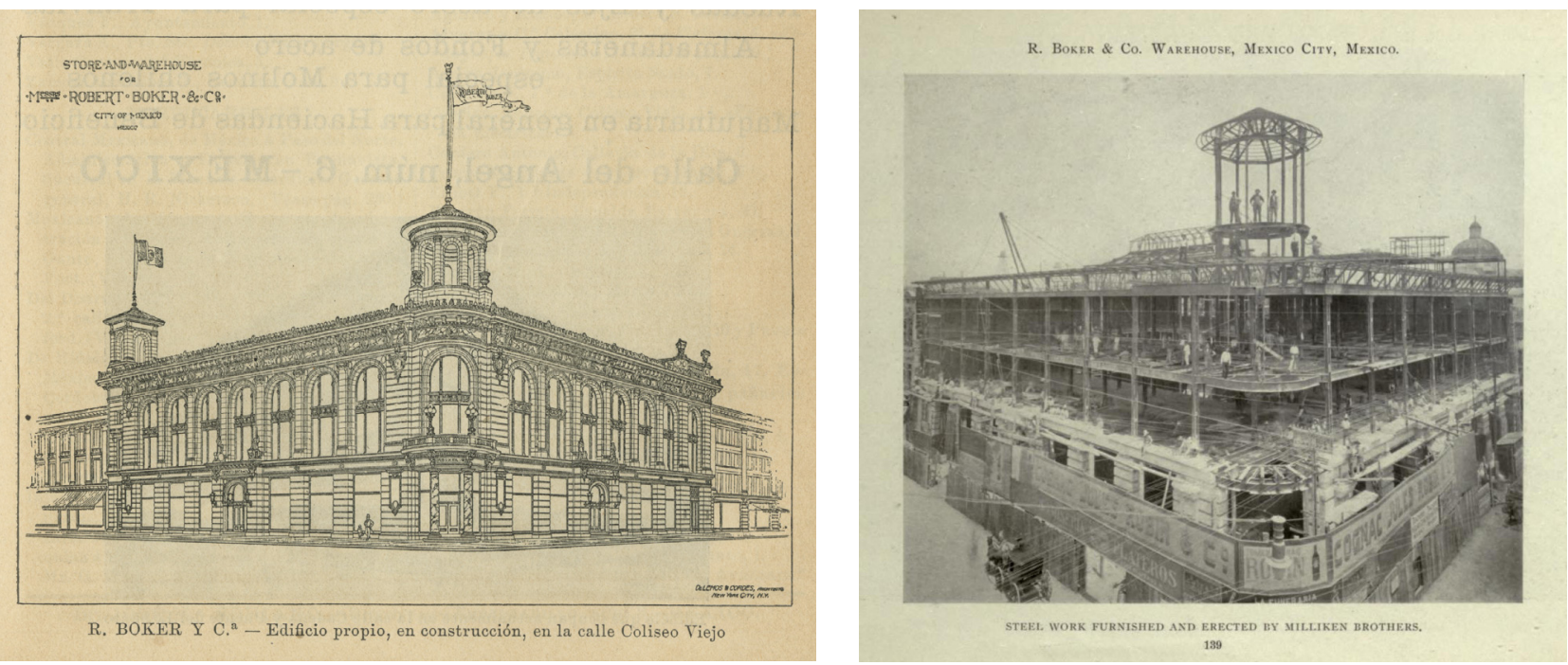


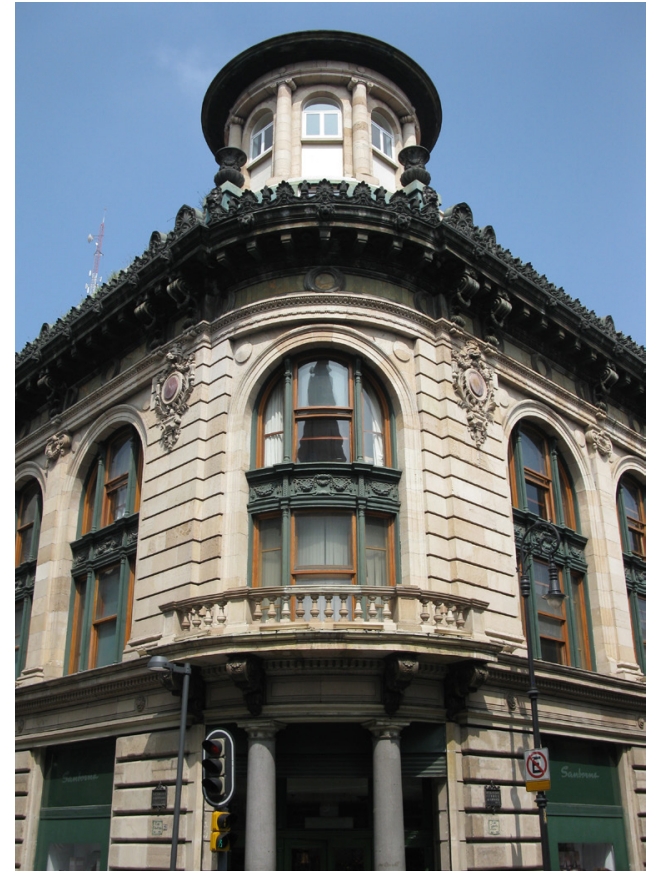

baja, en relación directa con la calle, con una imposta corrida que lo separa de las plantas superiores a lo largo de los dos frentes, mientras las amplias ventanas de esos dos niveles son agrupadas enfatizando la verticalidad bajo arcos de medio punto. La verticalidad se enfatiza también en la esquina, con columnas de inspiración dórica, ventanas con vidrios curvos - como el Fulton Building en Manhattan - y un mirador, a manera de templete, como remate en lo más alto del edificio. En las dos fachadas, con pilastras de inspiración jónica, se manifiesta la modulación de la estructura y todo el edificio es rematado con entablamento, cornisa y acróteras.

En común con las realizaciones de los arquitectos De Lemos \& Cordes la Casa Boker presenta, además de los órdenes y otras referencias clasicistas, elementos característicos de sus edificios comerciales: leones, representaciones del dios Mercurio y el monograma del consorcio comitente. Sin embargo, se integraban las posibilidades modernas de la construcción, no sólo con las columnas y vigas metálicas, sino con el empleo de cornisas y ventanería de producción industrial, convertidas en sello de carácter de los diseñadores (figuras 12, 13 y 14).

Un proyecto inmediatamente posterior a la experiencia en México con el edificio para la Casa Boker, el edificio para Adams \& Co. Dry Goods Store (figura 15), de 1900-1902, acusa un cercanísimo parentesco con el de la esquina de 16 de Septiembre e Isabel La Católica. En esos años, con el edificio para
R.H.Macy \& Co. Department Store, los arquitectos destronarian a Siegel-Cooper como la tienda más grande de Nueva York. De Lemos $\&$ Cordes competían con ellos mismos en el negocio de la arquitectura comercial.

Las críticas al edificio de Roberto Boker y Cía. por Antonio Rivas Mercado, arquitecto de larga trayectoria y prestigio en México, no se hicieron esperar:

No trataron de hacer una obra arquitectónica, sino un bombo comercial. El esqueleto de hierro fue chapeado de piedra y de mármol... Al lado de los materiales preciosos está la hoja de lata pintarrajeada en ménsulas y ornatos y en toda la cornisa de coronamiento... (Rivas Mercado, 1900: 132)

Rivas Mercado comparaba el nuevo edificio con la estructura metálica a la vista de El Palacio de Hierro, de clara referencia francesa. Pero en este otro caso, se trataba de un modelo distinto, el de la arquitectura comercial reciente en Nueva York, con la cual el arquitecto no estaría familiarizado y cuya suntuosidad se hacía obvio: "...los marchantes, al mirar el edificio, seguirán de frente exclamando mi dinero es para lo que me hace falta, no para pagar ese lujo superfluo" (Rivas Mercado, 1900: 132).

El notabilísimo edificio para Siegel-Cooper fue la experiencia inmediatamente anterior al proyecto en la Ciudad de México con la cual llegaba una exitosa firma de arquitectos, especialista en el diseño de edificios comerciales, y la internacionalmente acreditada ensambladora de estructuras metálicas.

\section{Los oportunos constructores para un pais en modernización}

El destacado edificio para Siegel-Cooper materializaba la colaboración entre De Le-
Figura 11. Edificio de Roberto Boker y Cía., 16 de Septiembre e Isabel La Católica, Ciudad de México. Arquitectura De Lemos $\&$ Cordes, construcción Milliken Brothers - Gonzalo Garita, 1898-1900. Detalle de la esquina. Foto: Mónica Silva, 2014.

Figuras 12 y 13 . Edificio de Roberto Boker y Cía., 16 de Septiembre e Isabel La Católica, Ciudad de México. Arquitectura De Lemos \& Cordes, construcción Milliken Brothers - Gonzalo Garita, 1898-1900. (12) La escalera en el espacio central del edificio, hoy desaparecida. Archivo Boker. (13) Fachada hacia la calle Isabel La Católica. Foto: Mónica Silva, 2014.
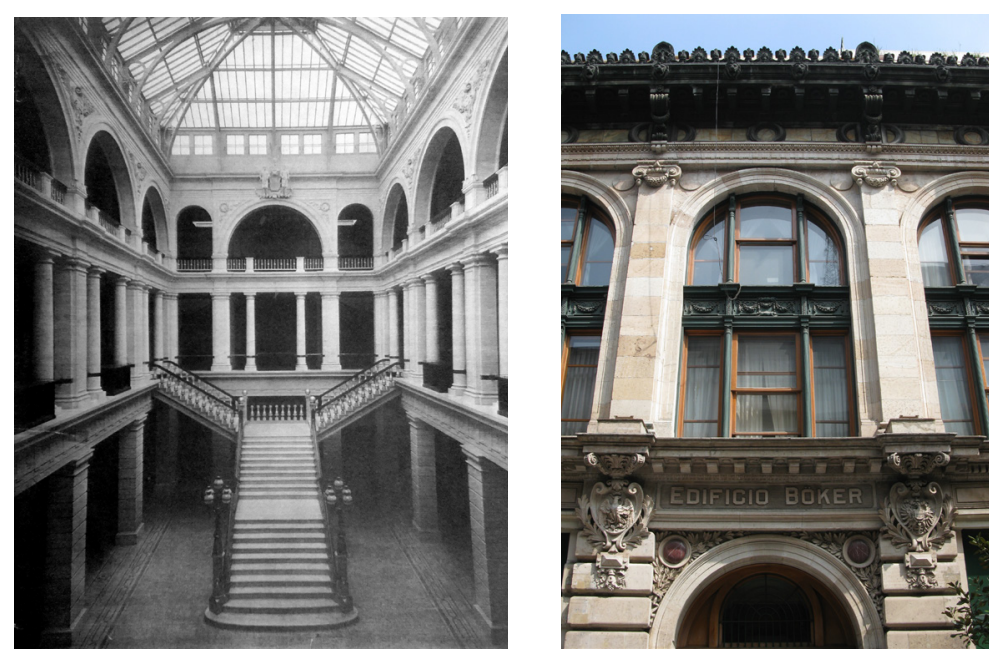
Figura 15. Adams \& Co. Dry Goods Store, New York, 675-691 Sixth Avenue. Arquitectura De Lemos \& Cordes, 1900-02. Foto: Mónica Silva, 2014.

Figura 14. Diseño de la cornisa. Milliken Brothers Catalogue: Second Export Edition. 1905. New York, 1905, lámina 92, p. 407. mos \& Cordes con la compañía establecida en 1857 por Samuel Milliken, padre de Edward y Foster Milliken, también con sede en Nueva York. Milliken Brothers se anunciaba en 1892 en todo lo vinculado con la manufactura, venta e instalación de material de hierro, entre las cuales destacaban sus puentes e instalaciones industriales, que constituian la mayor parte de los contratos, procedian de su enorme planta en Staten Island. ${ }^{12}$

El catálogo de la empresa en 1905 ofrecía columnas de fundición, fuentes, relojes y otros elementos arquitectónicos complementarios, además de tanques de agua, ventiladores, ventanas y puertas, asi como quioscos y otros elementos de mobiliario urbano (Milliken Brothers 1905). Poco después, en los tiempos cuando se declarase en quiebra, tendría a su cargo obras de tal magnitud e importancia como la estructura de 49 pisos del Singer Building, el cual pronto sería el edificio más alto del mundo, así como el contrato por las estructuras metálicas para la Pennsylvania Station de Nueva York (The New York Times, 1907).

Las estructuras metálicas, así como los elementos de fundición a la vista eran ofrecidos por lo fabricantes con diversos acabados: “...en 'Verde Antique' de varias formas en imitación de cobre envejecido, oxidados por exposición a la intemperie..." (Milliken Brothers 1905: 360). Este fue empleado en varios de los edificios por De Lemos \& Cordes y muestran la colaboración cercana entre las dos compañías. De ahí que no sorprende encontrar el diseño de la cornisa del Edificio Boker en el

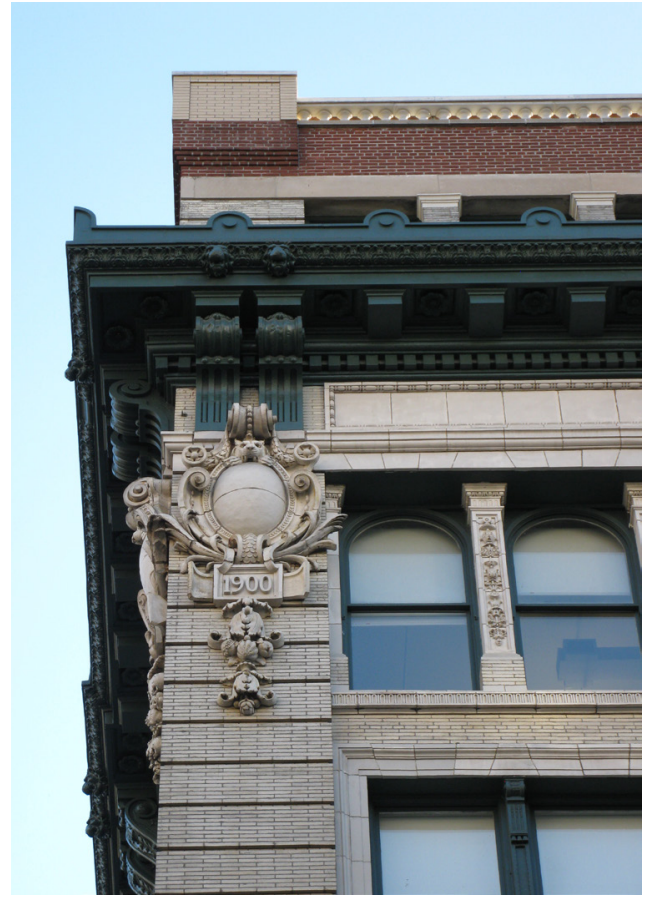

catálogo de Milliken Brothers: "Esta cornisa tiene 10 pies de altura y está hecha completamente de lámina de cobre, exceptuando los paneles internos del friso, los cuales están relleno con losas de mármol" (Milliken Brothers, 1905: 405).

La presencia de la empresa en el país puede seguirse a partir de la prensa local editada en inglés. En el diario The Two Republics se reseñó la visita de Foster Milliken “...para inspeccionar el progreso de las obras en el edificio de Roberto Boker y Cía...”. El periódico continuaba su reseña describiendo:

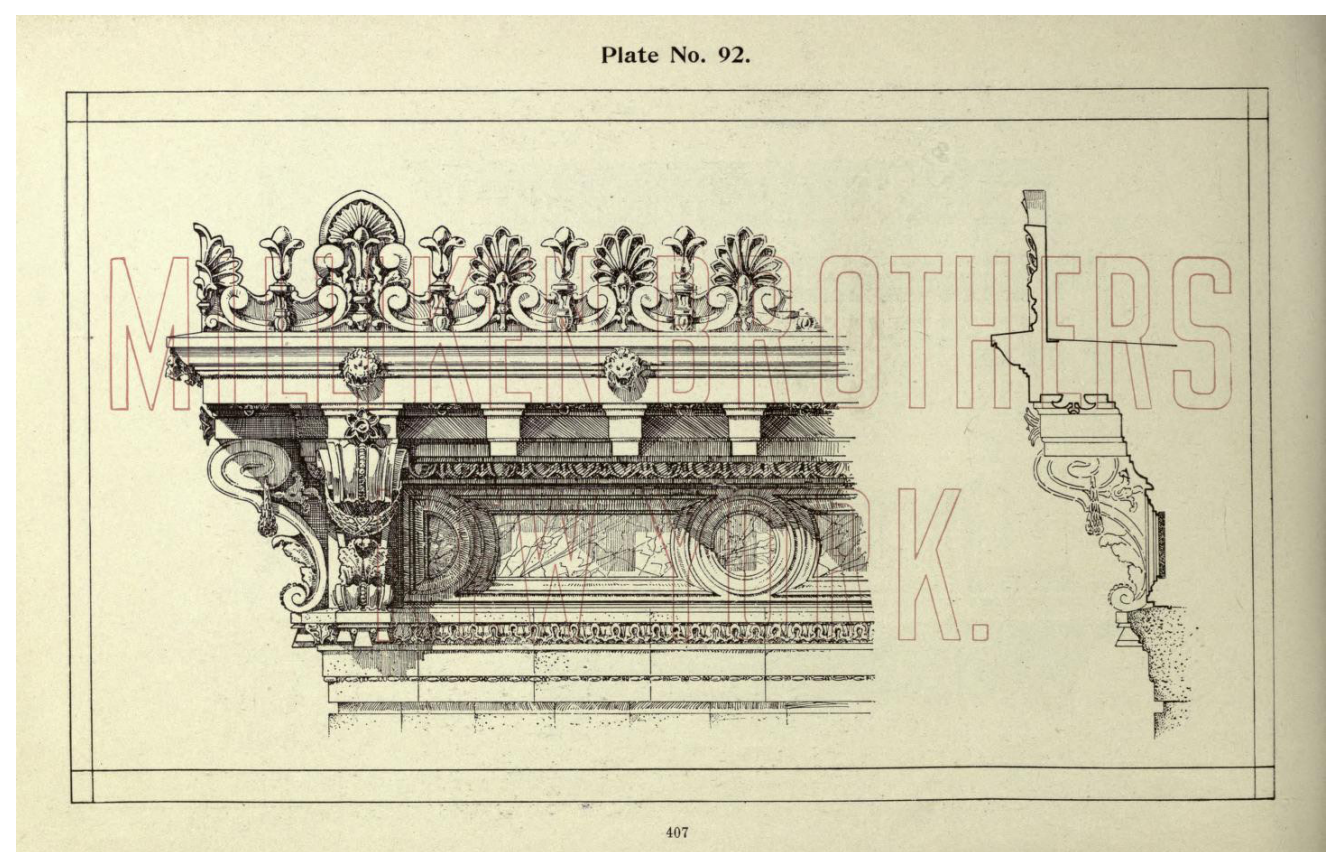


La obra de acero del segundo piso está bien encaminada, aún cuanto estuvo retrasada debido a fallos en la llegada del material. Cuando el edificio esté terminado, habrá sido calculado para resistir cualquier terremoto posible ya que no está soportado por sus paredes, las cuales pueden ser parcialmente derribadas por un impacto sin afectar la estabilidad del edificio, ya que éste se soporta en el entramado de acero. (S.A., The Two Republics, 1899)

Las ventajas en el suelo sísmico mexicano eran exaltadas, así como la novedad de una estructura con esqueleto de acero, destacada como "el primero de su clase alguna vez construido en México". La afirmación no era tan cierta, pues aún cuanto era una de las primeras grandes estructuras metálicas en México, los edificios de la joyería La Esmeralda o el ya mencionado Palacio de Hierro y otros más le habrian precedido.

En su paso por la Ciudad de México, Foster Milliken venía de Honolulu, luego iría a Guadalajara y Tampico, para luego dirigirse a La Habana. A sus obras de carácter urbano habrian de sumarse numerosas instalaciones industriales en Hawaii, Johannesburgo, Ciudad del Cabo, Puerto España, diversas localidades en Cuba, México o Siberia. ${ }^{13}$

Si De Lemos \& Cordes traía una importante experiencia con edificios comerciales y corporativos, no era menos la que traía Milliken Brothers, en proceso de expansión desde 1890. Entre las primeras destaca la del edificio que el industrial cervecero Ellis Wainwright, había encargado a Dankmar Adler y Louis Sullivan, obra paradigmática de la arquitectura moderna. Empresas y empresarios extranjeros en diversas ciudades del mundo hacian de éste un tiempo de globalización para la arquitectura y sus referentes.

Algunos trabajos de Milliken Brothers en México se vincularon a funciones de indole industrial, con estructuras para el Muelle-Depósito en Tampico, luego que se incendiara la primera estructura en 1898, talleres del sistema de tranvías de la Ciudad de México, el gran edificio de las instalaciones de la Compañia Mexicana de Gas y Luz Eléctrica.

\section{La experiencia para cimentar modernas estructuras en la Ciudad de México}

Si bien el edificio para Roberto Boker y Cía. no fue la primera tienda departamental ni tampoco el primer edificio de oficinas moderno en la Ciudad de México, si fue el primero con el sistema de fundaciones de em- parrillado metálico, conocido con el genérico apelativo de "sistema Chicago", aun cuando en la historia de las cimentaciones de Chicago había continuas innovaciones (Peck 1948: 21-25). Fue el sistema de cimentación mayormente empleado a orillas del lago Michigan así como en la Ciudad de México hasta la difusión del concreto armado hacia 1902.

Para ese entonces Gonzalo Garita se entendía bien con el fangoso subsuelo de la capital mexicana, pues demás de haber trabajado en las obras de El Centro Mercantil, ya el ingeniero militar había hecho equipo con Daniel Garza para ocuparse de la cimentación del edificio para el Banco Hipotecario (S.A., El imparcial, 1907). Sin embargo, el edificio Boker sería la primera obra que daría gran notoriedad al ingeniero que trabajaba junto con el representante de Milliken Brothers, William Davis. La descripción de las obras de cimentación del edificio, que se extienden bajo la acera de las calles en aras de distribuir el peso de la estructura en la mayor área posible, deja ver la implementación de técnicas y materiales modernos en el mismo desde el subsuelo:

El área disponible media 2,215 metros, la cual fue excavada en toda su extensión a cerca de dos metros de profundidad, rellenándose con concreto compuesto de piedra triturada, arena y cemento. Para poder colocar el concreto en el agua del subsuelo, sin que esta se llevara el cemento antes de fraguar, se metió en 24,500 sacos, en los cuales se gastaron 50,000 metros de manta resistente. La fuerza del concreto se reforzó después con un emparrillado de acero, quedando asi preparado el terreno para la edificación. (S.A., El imparcial, 1900)

Del mismo modo en que las obras de cimentación fueron consecuentes con los esquemas en el catálogo editado por Milliken Brothers en 1905, la descripción del sistema constructivo empleado en el edificio Boker lo es con las ilustraciones en el mismo:

...no menos notable fue la construcción de los techos, en los que, además de las viguetas de hierro, se emplearon tela de alambre reforzada por varillas y una capa de concreto de cemento.

Para formar la azotea, se hizo uso del mismo concreto en buenas proporciones, cemento alemán puro, hojas de cartón alquitranado, entre las capas de cemento y ladrillo vidriados. (S.A., El imparcial, 1900) 

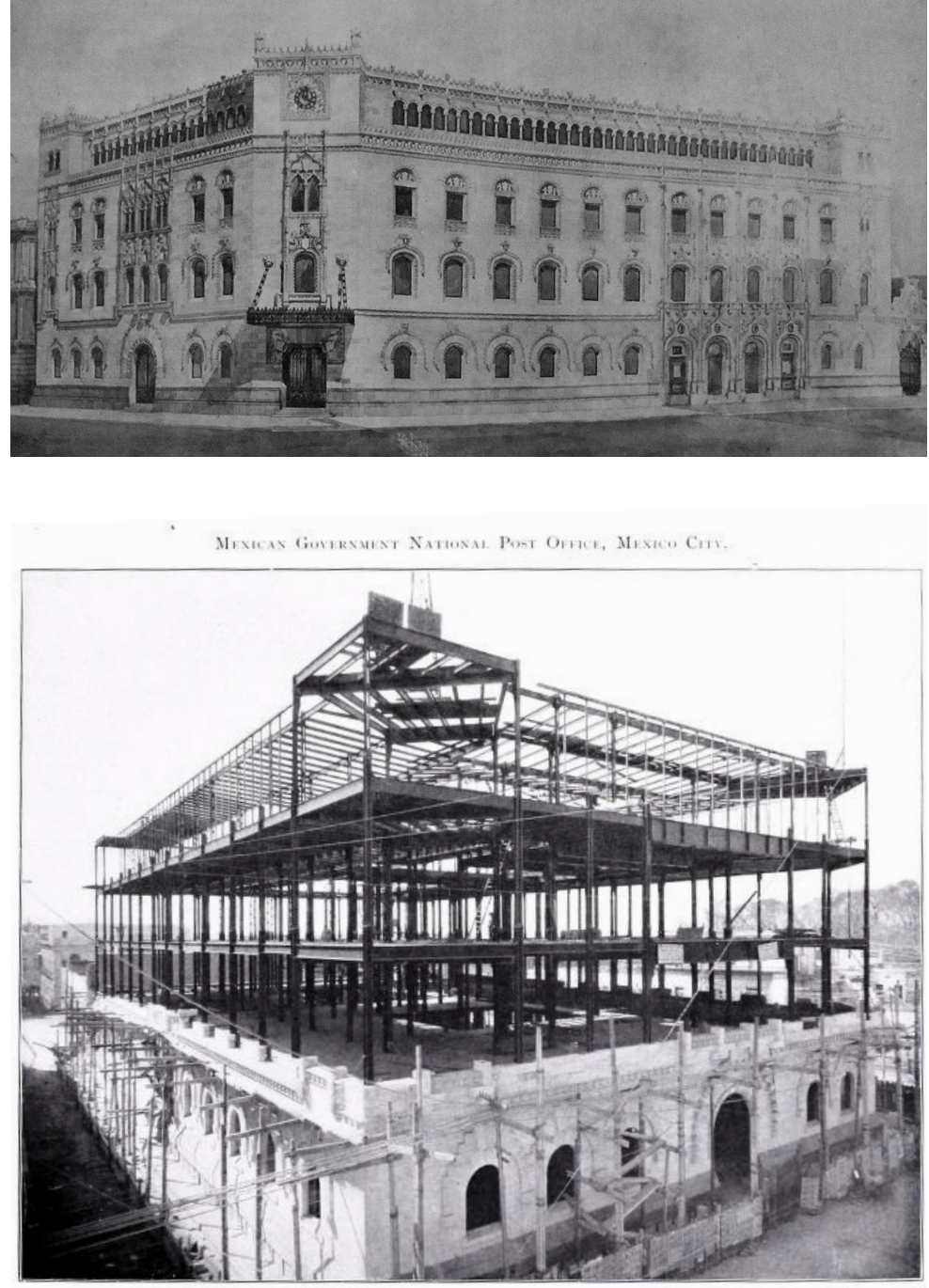

STEEL WORK FURNISHED AXD ERECTES LY AULLLIKEN BROTHERS 149

Figuras 16 y 17. Palacio de Correos, Ciudad de México. Arquitectura Adamo Boari, construcción Milliken Brothers, Gonzalo Garita, 1902-1906. (16) Perspectiva del edificio. "La nueva Casa de Correos: Colocación de la primera piedra". El mundo ilustrado, 21 de septiembre de 1902, s.n. (17) Vista del edificio en construcción. Milliken Brothers Catalogue: Second Export Edition. 1905. New York, 1905, lámina 92, p. 149 .
La descripción no coincide, sin embargo, con los materiales con los que efectivamente fue construido el edificio. Posteriores trabajos en el mismo permitieron conocer que sobre las varillas del sistema constructivo empleado por Milliken Brothers, un relleno de tezontle sustituyó al concreto (entrevista a Pedro R. Boker en agosto de 2013). La ligereza de ese material, así como su baratura, funcionaron durante muchos años en el edificio. La experiencia de Garita tal vez sería la razón para este cambio de prácticas, pues ante la cimentación no había opciones, pero la liviandad de la estructura era un requisito fundamental y Garita conocía los recursos locales.

Del mismo modo en que el Edificio Boker abrió las puertas para la realización de otros proyectos a los arquitectos y a los contratistas de la estructura metálica, la construcción de la notable tienda abrió nuevas posibilidades al trabajo de Gonzalo Garita. El ingeniero era garantía para la cimentación de estructuras modernas y así también haría notar su experiencia en la construcción de la casa principal de Correos (1902-1907), según proyecto arquitectónico de Adamo Boari (1863-1928).

\section{Correos: arquitecto italiano, ingeniero mexicano, estructura neoyorkina}

El edificio de Correos resultaba una interesante opción de trabajo para el arquitecto de origen italiano por varios años residenciado en Chicago y vinculado a México a partir del concurso para el Palacio Legislativo Federal en 1897. Hacia 1898 tuvo su oficina en el Steinway Hall, el edificio que sirvió de base al grupo conocido como The Eighteen. ${ }^{14} \mathrm{El}$ trabajo internacional de Adamo Boari lo proveyó de vínculos y conocimientos que, obviamente, resultaron reflejados en sus proyectos (Condello, 2004). ${ }^{15}$

Más adelante, en 1899 se publicaba que Boari traía planos de rascacielos para su construcción en México (S.A., The Mexican Herald, 1899). La noticia lo vinculaba con los modernos edificios de oficinas que ya iniciado el siglo XX eran referentes de modernidad:

Un arquitecto americano que hablaba hace poco tiempo sobre el asunto que nos ocupa, decía que se acerca el tiempo en que se verán en México edificios en todo semejantes a los "skyscrapers" de que se forma el centro de las grandes ciudades americanas. La parte pintoresca de la ciudad perderá indudablemente con estos cambios, mientras que las comodidades que ahora nos son casi desconocidas, serán de uso frecuente entonces. Electricidad por todas partes, elevadores, luz... (S.A., El imparcial, 1902a).

Desde 1897, cuando vino a México por primera vez, Boari fue integrándose al entorno de arquitectos y constructores locales. El vínculo con Gonzalo Garita quedaría establecido gracias al conocimiento que este último tenía de los sistemas constructivos norteamericanos. De ahí que cuando se difundieran las primeras noticias acerca de la construcción del Teatro Nacional, aun sin proyecto, se precisaría que estaría a cargo de Adamo Boari y su construcción a cargo de Gonzalo Garita (S.A., El tiempo, 1901). Seis meses más tarde ocurría algo similar con respecto al edificio para el servicio de Correos, con la indicación: "La construcción es del tipo más moderno de hierro y acero para su estructura interior, con techos a prueba de fuego..." (S.A., El popular, 1901).

En 1898 Boari se refería a la incombustibilidad de la "Steel Construction", la cual 
conocia desde Chicago y que ahora empleaba junto a Garita en la Ciudad de México. Definía además la "Steel and brick construction", aquella cuyos "...muros no son hechos ya para sostener sino para ser sostenidos", como opción adecuada para la condición sísmica de la Ciudad de México, así como para hacer una arquitectura cuyas formas debían abandonar el ordenamiento clásico para abrir paso a la pura creatividad decorativa: "Ciertamente, si la construcción americana toma auge en México, esto no quiere decir que arraigue aquí el gusto americano: el sistema de fabricación no tiene nada que ver con la forma estética exterior" (S.A., Boari, 1898). Su edificio para Correos así lo manifestaba (figuras 16 y 17).

La construcción del edificio fue seguida por la prensa capitalina y se haría pública la llegada de la estructura metálica desde los Estados Unidos. Luego de la colocación de la primera piedra, el edificio de Boari, con estructura de Milliken Brothers a cargo de Gonzalo Garita sería descrito:

La altura es de 28 metros y será el más alto edificio de México hasta el presente.

Es el primer edificio construido enteramente a prueba de fuego y "steel construction". Los frecuentes terremotos y movimientos sísmicos no tendrán ninguna influencia sobre esta armadura de acero, completamente rigida. (S.A., El imparcial, 1902b)

El tema estilístico trataba de definirse en la combinación de muy diversas fuentes de inspiración buscando justificar que no fueran las del clasicismo tradicional. En ese sentido no puede dejar de señalarse la coincidencia de detalles en la fachada (figuras 18 y 19) del edificio en México con un notable rascacielos pionero de la escuela de Nueva York: el Corbin Banking Company Building, obra de Francis H. Kimball en 1888.

Las publicaciones mexicanas de esos años enfatizaron la similitud funcional y el carácter urbano del nuevo palacio de Correos con su homólogo en Nueva York, la City Hall Post Office (1880, demolida), en cuanto a su funcionamiento e instalaciones (S.A., El imparcial; 1905-1906). Los modelos franceses eran cada vez más lejanos de la modernidad de la arquitectura norteamericana señalada por muchas vías.

En medio de contratos en diversos lugares del mundo, el nuevo Teatro Nacional, el edificio de Correos, la estructura para el $\mathrm{Pa}$ lacio Legislativo, así como pronto la del edificio Sede de la Secretaría de Comunicaciones,
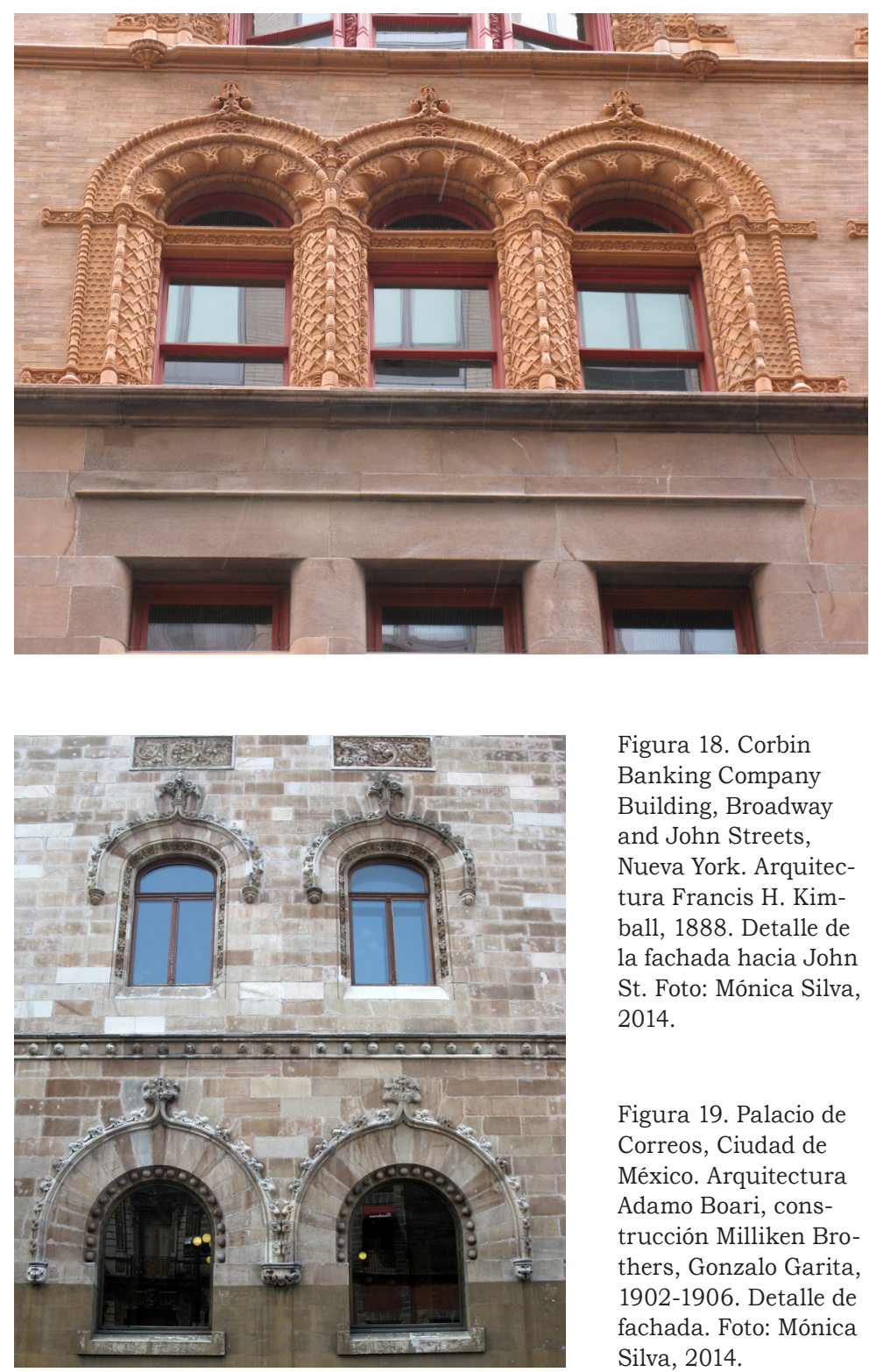

Figura 18. Corbin Banking Company Building, Broadway and John Streets, Nueva York. Arquitectura Francis H. Kimball, 1888. Detalle de la fachada hacia John St. Foto: Mónica Silva, 2014.

Figura 19. Palacio de Correos, Ciudad de México. Arquitectura Adamo Boari, construcción Milliken Brothers, Gonzalo Garita, 1902-1906. Detalle de fachada. Foto: Mónica Silva, 2014. además de otros en el país, hacian de México una de las sedes de los importantes negocios de Milliken Brothers. ${ }^{16}$ De la empresa derivaba en 1903 la nueva firma Garret y Hawke, de Warren Garret y John Hawke, quienes habian sido empleados de la empresa en la capital mexicana y ahora se independizaban con contratistas de estructuras metálicas (S.A., The Mexican Herald, 1903). El establecimiento local de los hermanos Milliken era un negocio formal, como también lo era para una importante compañia de seguros también neoyorkina.

\section{Encuentro en México entre arquitectos, comitentes y constructores neoyorquinos}

Mientras la constructora Milliken Brothers ejecutaba trabajos en diversas latitu- 
des, De Lemos \& Cordes, luego de la Casa Boker, continuaba su desempeño en el ámbito comercial de Nueva York. Uno de sus edificios más conocidos, la tienda abanderada de R.H.Macy \& Co. (figura 20), era parte de esa experiencia en que monogramas empresariales se encontraban con la composición de tradición académica internacional y las estructuras metálicas de Milliken Brothers. Las cariátides del escultor John Massey Rhind, en la fachada hacia la calle 34, hicieron parte de la importante función complementaria que la escultura tenía para la arquitectura.

En la Ciudad de México, antes que esta historia de arquitectos y constructores, entre 1886 y 1889 avisos en primera página en los periódicos locales en inglés harian publicidad a The Mutual Insurance Company of New York como la más antigua aseguradora de los Estados Unidos (S.A., The Two Republics, 1886). El nombre de la compañía era simplificado en castellano a partir de 1888 cuando sería simplemente "La Mutua", aunque los avisos incluyeran su designación en inglés. ${ }^{17} \mathrm{La}$ aseguradora continuaría funcionando en México, mientras se construyeron los edificios de El Centro Mercantil y más tarde la Casa Boker.

Una de las primeras noticias sobre la construcción del edificio de seis pisos para "La Mutua" fue publicada en 1901 a raíz de una disculpa por no poder efectuarse la presentación de los planos y especificaciones debido al cambio de ubicación del proyecto a que obligaba el plan gubernamental con el predio dispuesto: El enorme terreno estaba siendo dispuesto para la construcción del nuevo Teatro Nacional y la compañia asegu-

Figura 20. R.H. Macy $\&$ Co. Department Store, Broadway and West 34th Street, New York, 1901-1902. Arquitectura De Lemos $\&$ Cordes, construcción George A. Fuller Compan. Detalle del acceso por West 34th St. Foto: Mónica Silva, 2014. radora debía conseguir otro para la construcción de su sede (S.A., The Mexican Herald, 1901). La prioridad la tenía el nuevo Teatro Nacional, proyectado por Boari, con estructura del famoso arquitecto e ingeniero William H. Birkmire, fabricada por Milliken Brothers y que supervisaría Gonzalo Garita.

El compromiso de hacer público el proyecto se cumplió casi tres años más tarde, cuando en primera página, con la reproducción de la perspectiva del edificio firmada por los arquitectos, se anunciará la construcción del edificio en la cuadra vecina al primer predio (S.A. El imparcial, 1904; S.A., The Mexican Herald, 1904).

La compañía aseguradora había construido sedes en diversas ciudades. Había estrenado hacia 1893 un edificio en el mismo entorno de los edificios diseñados por De Lemos \& Cordes en Manhattan ${ }^{18}$ y mientras se resolvía el emplazamiento del edificio en México, construía su sede en Ciudad del Cabo, según diseño del arquitecto William Black, con estructura de Milliken Brothers (Radford, 1998: 45).

Gonzalo Garita, en vínculo con las empresas internacionales proyectistas y constructoras, estaba a la cabeza de la sede de "La Mutua" en la Ciudad de México, con el agente local de los constructores de la estructura metálica, T.E. Rhoades, trabajando según la propuesta arquitectónica elaborada por De Lemos \& Cordes y cuyo diseño estructural estuvo a cargo de A.R.Whitney \& Co., conocidos ingenieros y contratistas de estructuras metálicas con oficina en Broadway, Nueva York.

La experiencia con la cimentación de la Casa Boker, así como el sistema constructivo de Milliken Borthers para los entrepisos incombustibles fueron referencia para la descripción del edificio al público especializado ("El edificio de La Mutua” 1906: 259-263).

Se anunciaba en 1904: "Habrá diez cariátides, del estudio de un famoso escultor de Nueva York, que formarán las columnas de las ventanas del segundo piso sobre la entrada principal..." (S.A., El imparcial, 1904). Ubicadas en la fachada principal, estas pudieron ser del escultor J. Massey Rhind, quien había ejecutado las de la tienda de R.H.Macy. ${ }^{19}$ Del mismo modo, las lámparas especialmente diseñadas para el edificio serian de fabricante norteamericano. Las coincidencias entre proyectistas y contratistas iban más allá de la estructura.

La altura del edificio - hoy sede del Banco de México - llegaría a veintidós metros, límite fijado por el Ayuntamiento en 1903. Con sólo 


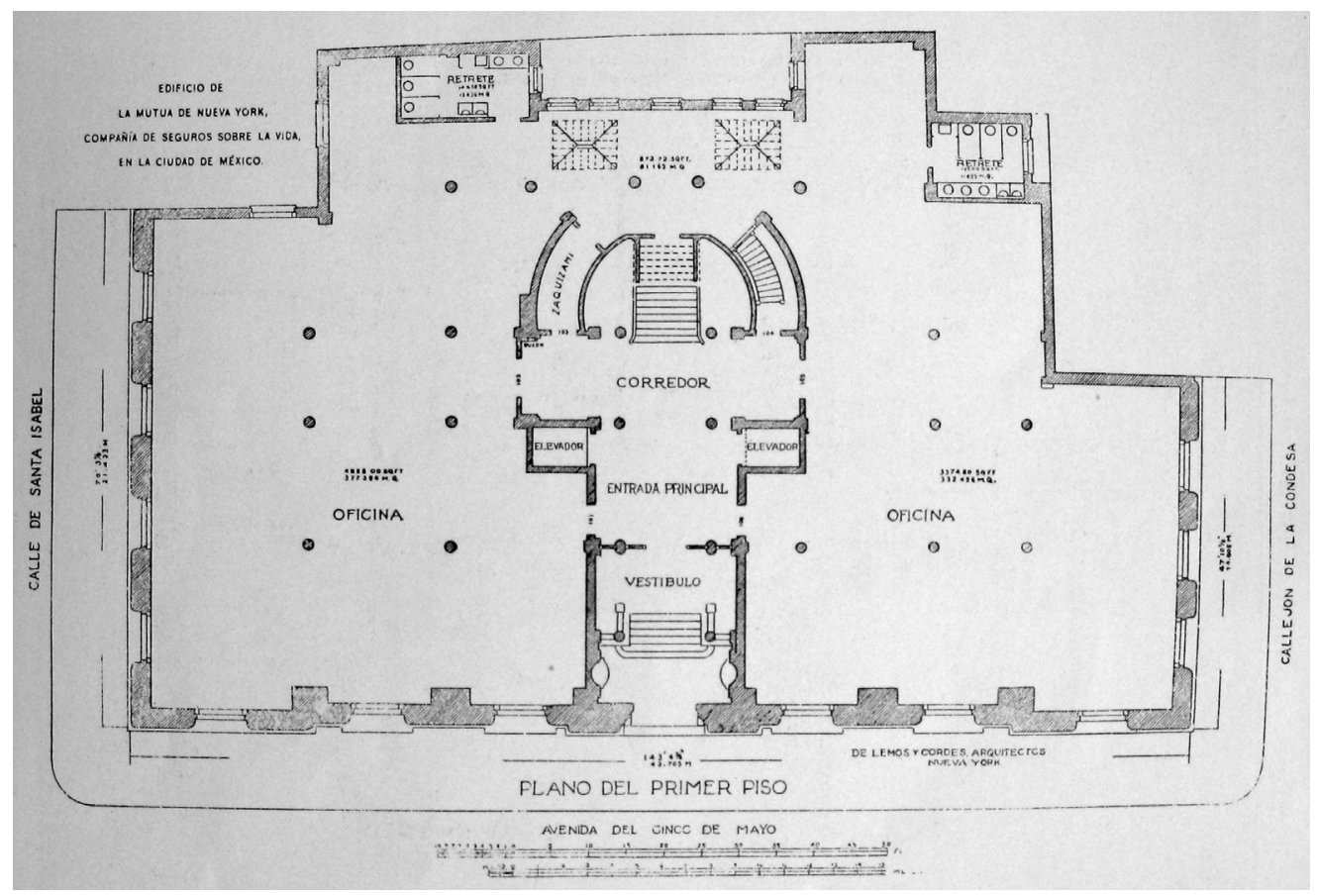

Figuras 21 y 22

Edificio The Mutual Insurance Company of New York, "La Mutua", 5 de Mayo, Ciudad de México. Arquitectura De Lemos y Cordes; construcción Milliken Brothers, Gonzalo Garita. (21) Planta baja. "El edificio de La Mutua”. El arte y la ciencia, vol. VII, núm. 10, abril 1906, p. 259. (22) Detalle del acceso por avenida 5 de Mayo. Foto: Mónica Silva, 2014

planta baja, tres niveles de oficinas y uno de habitaciones por encima de la cornisa - con el nombre de la compañía en las dos fachadas - debido a sus proporciones, se asociaba a los altos edificios de oficinas neoyorkinos. Las fachadas, a modo de palazzo renacentista - un tipo arquitectónico muy racional y por ello recurrido en la historia - daban suficiente importancia a las funcionales ventanas, con lo cual "...la distribución de la luz se ha hecho de tal manera que cada oficina tendrá una iluminación perfecta" (S.A., El imparcial, 1904). La electricidad era conocida en la ciudad, pero no por ello dejaba de anunciarse que el edificio tendria "una completa instalación de luz eléctrica”.

La simetría de la fachada principal (figura 21) acusaba el partido arquitectónico, diferenciado de los precedentes que combinaron otras funciones comerciales con oficinas, especialmente de la anterior experiencia conjunta de arquitectos y constructores. Al pasar el vestíbulo, con acceso en el eje central del edificio, un espacio de circulación contribuye a distribuir a los usuarios entre la escalera monumental y los elevadores a ambos lados (figura 22).

El nuevo edificio (figura 23) tendría a ambos lados del vestíbulo "dos grandes y rápidos elevadores, que estarán en movimiento constante" y a sus facilidades se añadía "un completo circuito telefónico con sus conexiones correspondientes para cada oficina". Entre las instalaciones seguían teniendo importancia los sanitarios:

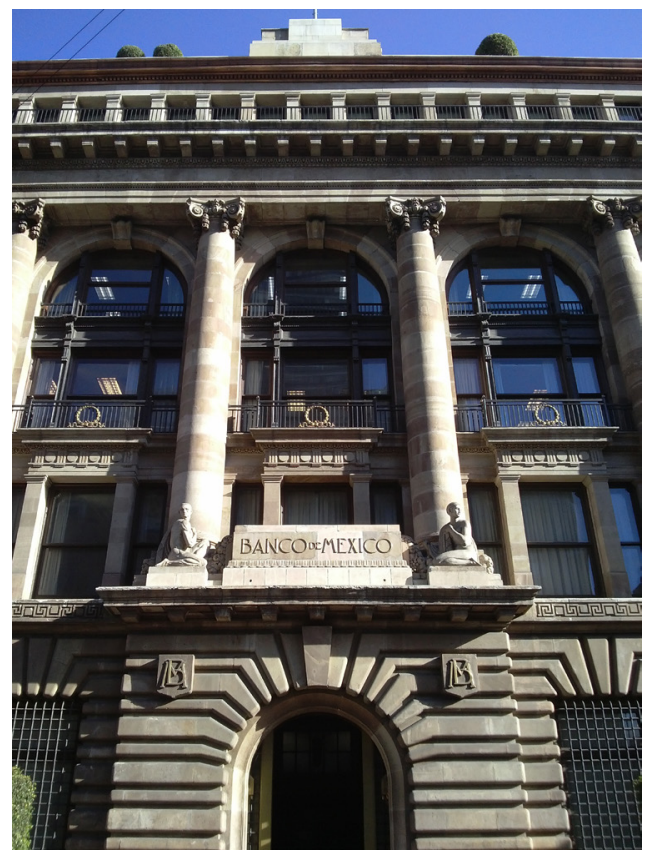

Los amplios lugares para "toillete" de sistema moderno, asi como también los lavabos de mármol en cada oficina, abastecimiento amplio de agua de pozo artesiano, y todos los pequeños refinamientos que contienen los grandes edificios de los Estados Unidos, hacen de éste, indudablemente, el único de su género en la República. (S.A., El imparcial, 1904)

La imagen de la ciudad moderna se vinculaba a los hombres de negocios, a las avenidas con rascacielos y los consorcios internacionales que dibujaban un nuevo mundo comercial 
Figura 23. Edificio The Mutual Insurance Company of New York, "La Mutua", 5 de Mayo, Ciudad de México. Arquitectura De Lemos y Cordes; construcción Milliken Brothers, Gonzalo Garita. Vista del edificio recién terminado. Manuel Torres Torija, El florecimiento de México. México, Francisco Trentini, 1904, p. 60 .

Figura 24. Edificio Mutual Insurance Company of New York, 5 de Mayo, Ciudad de México. Arquitectura De Lemos y Cordes; construcción Milliken Brothers, Gonzalo Garita. Detalle de la fachada. Foto: Mónica Silva, 2014. en el mundo americano. ${ }^{20}$ El edificio para The Mutual Life Insurance Company of New York se insertaba en la gestión de los altos edificios de oficinas:

Habrá como noventa oficinas, de tal manera arregladas que puedan arrendarse por separado o en "suite".

La Dirección General de la Compañía ocupará el segundo piso, arrendándose los demás a precios razonables, dadas las comodidades que ofrecen, las que harán época en la construcción de edificios para oficinas en esta ciudad. (S.A., El imparcial, 1904)

Las plantas de los primeros niveles, entonces, muestran la distribución de los espacios gerenciales de la compañia, mientras los
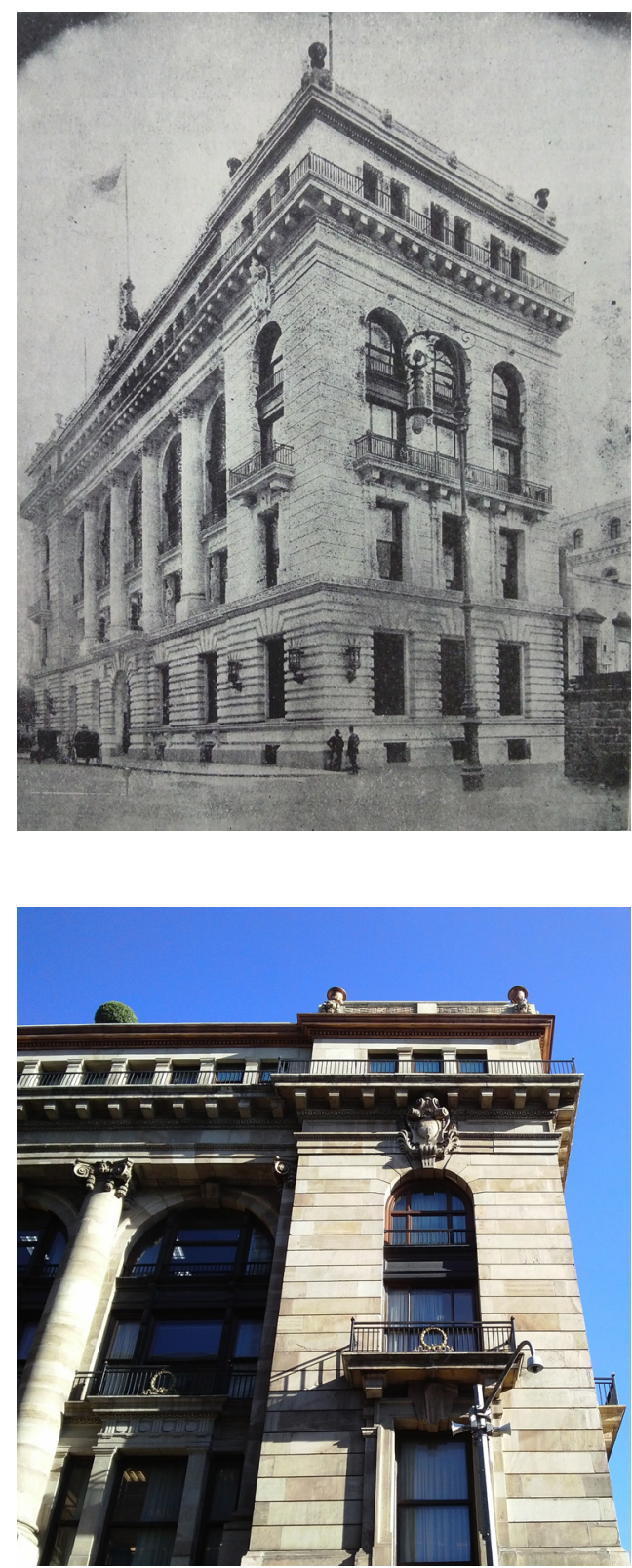

otros corresponden a la secuencia de oficinas con dimensiones similares y posibilidades de asociación o partición de acuerdo al requerimiento de los inquilinos. Como lo previsto por Louis Sullivan para los altos edificios de oficinas, en el de "La Mutua" se construyó “...un piso bajo, que ofrece fácil acceso a toda la maquinaria, plomería, conductos eléctricos, etc." ("El edificio de La Mutua" 1906: 262).

El edificio inaugurado con una gran fiesta con destacados asistentes de la vida política, diplomática y empresarial de la ciudad, se convertiría, como lo deseaba la empresa promotora, en uno de los referentes de la modernización de la Ciudad de México (figura 24).

\section{Quiebra, defunciones y fin de una historia...}

La participación conjunta de la firma de arquitectos de Theodore William Emile De Lemos y August William Cordes con la internacionalmente conocida empresa constructora de Edward Fullerton y Foster Milliken vinculan, muy especialmente, al edificio de la Casa Boker y al de "La Mutua" con toda una era de la construcción de edificios comerciales y de oficinas en Nueva York y en diversos lugares del mundo.

El ocaso de una y otra empresa de profesionales se iniciaría con la muerte de sus socios. En noviembre de 1906, con sólo 44 años, fallecía Edward F. Milliken, con lo cual la gran empresa quedaba en manos de su hermano menor. Obviamente, la mayor preocupación en México residia en el cumplimiento de los contratos, pero el evento no los afectaria, aunque la zozobra crecía con las novedades en cuanto a la solvencia financiera de la empresa. En junio de 1907 se reportaron los problemas causados por inversiones imprudentes (The New York Times, 1907).

El New York Times reseñaba los problemas económicos de la firma y tres dias después lo hacía el Mexican Herald. La propia instalación industrial habría sido la causa de la quiebra de una industria de 50 años. Pero la empresa continuaría cumpliendo sus compromisos mediante la compra de acero, lo cual, según la prensa neoyorkina, resultaba más favorable en esos momentos que su producción. Entre los contratos de la compañía en México, el edificio sede de la Secretaría de Comunicaciones y Obras Públicas estaba casi terminado y el material para el Teatro Nacional estaba siendo suplido con regularidad (S.A., The Mexican Herald, 1907a). La situación económica era descrita por el representante de la firma en México como algo 
temporal (S.A., The Mexican Herald, 1907b). Pocos meses después vendría Foster Milliken a México, acompañado de su contador (S.A., The Mexican Herald, 1907c).

Todavia en 1913 Milliken Brothers mantenía su oficina en la Ciudad de México, ya terminados los contratos del Teatro y a la espera de una situación política más clara para cumplir con la estructura del Palacio Legislativo (S.A., The Mexican Herald, 1913). Sin embargo, los conflictos politicos se orquestarian para que las dos mayores piezas de arquitectura porfiriana quedaran en vilo.

Dos meses antes de la quiebra de los constructores de estructuras metálicas, Theodore De Lemos fallecía en Nueva York. La nota necrológica destacaba el trabajo del arquitecto en Alemania, donde había diseñado edificios para el ejército, en los Estados Unidos, su país de adopción, y en México (The New York Times, 1909). Ellas vinculaban directamente a la capital mexicana con la historia de la arquitectura moderna internacional. Las fachadas de los edificios evidencian un parentesco que hoy podemos entender en el contexto de difusión global de materiales, técnicas y formas. Los edificios neoyorquinos asentados en la Ciudad de México son el resultado del manejo compositivo de tradición académica que caracterizó la formación de los arquitectos en combinación con los modernos materiales empleados tanto para la estructura como para los complementos y acabados, como resultado de una gerencia de la construcción internacional que gestionaba contratos más allá de las fronteras de una nación u otra.

Todavía en 1912, ladrillos, ornamentos de piedra en contraste y cornisas en "Verde Antique" seguian protagonizando algún edificio empresarial en Nueva York. La historia de la arquitectura muestra, con estos ejemplos y otros, la verdadera complejidad de un tiempo en que el trabajo de profesionales formados en la tradición historicista internacional no tenía respuestas novedosas ante la oferta de toda clase de disponibilidades modernas.

Otros edificios de oficinas se construyeron por estos tiempos en la Ciudad de México. Sus vínculos empresariales, nacionales e internacionales, siguen aún pendientes de investigación. Su imagen externa y los pocos datos disponibles los vinculan a esta historia. Es el caso de la sede de la Asociación Cristiana de Jóvenes (YMCA) en la esquina de las calles Morelos y Balderas, inaugurado sólo hasta la puerta - sin ingresar - por el presidente Porfirio Díaz entre las festividades del Centenario de la Independencia. Es también el caso del edificio de los Ferrocarriles Nacionales, durante cuyas obras pasearía con frecuencia Gonzalo Garita y cuyas esculturas, ventanería y composición de fachadas en general, acusan vínculos del trabajo de Isidro Díaz Lombardo que esperan por ser descubiertos.

La preservación del imaginario de la modernidad en la Ciudad de México requiere una revisión desde los vínculos entre los inmuebles con sus muchos realizadores, más allá de los nombres de arquitectos. Su identidad se enriquece con las historias que vinculan a unos y otros, entre unos y otros encargos y entre unos comitentes y otros.

En ese sentido, las razones por las cuales se integraron profesionales extranjeros en la arquitectura capitalina fueron las enormes oportunidades de una economía en expansión y una ciudad en desarrollo. En ella se insertó una tipología de estructuras en que la oferta de técnicas y materiales constructivos llegaba oportunamente a una capital en optimista crecimiento. Era una ciudad en la que todos - comerciantes, empresas nacionales y extranjeras, profesionales de la construcción, nacionales y extranjeros - exploraban nuevas posibilidades de trabajo.

\section{Notas}

1 La historia de ambas empresas ha sido escasamente abordada. Algunas publicaciones en la internet refieren a algunos de los edificios de la sociedad De Lemos \& Cordes en Nueva York, sin que se les inserte con una perspectiva critica en la arquitectura de su tiempo; en México la firma fue señalada por Israel Katzman y en adelante la referencia ha sido repetida sin ampliar los datos sobre los arquitectos o su trascendencia (Katzman 1973: 356). En cuanto a la historiografía referida a Milliken Brothers, el capitulo "Shipping American Skycrapers Abroad: Milliken Brothers" en el libro de Jeffrey Cody, Exporting American Architecture, 1870-2000, está basado en la información que proporciona el catálogo publicado por la empresa en 1905, el mismo referido directamente en estas páginas (Jeffrey 2003: 15-20). La información ahí citada complementa el artículo de Dennis Radford "The Early History of the Tall Building in the South African City (Radford1 1998).

2 Entre 1821 y los últimos años del siglo XIX las mayores importaciones llegaron desde Inglaterra, luego de Estados Unidos y en tercer lugar de Francia; entre 1900 y 1910 más del 50\% de llegaba desde los Estados Unidos, poco menos 
de Inglaterra y de Alemania, y en cuarto lugar desde Francia (De la Peña 1999: 142).

3 En el contexto mexicano y en cuanto al alcance angloparlante, pueden citarse ediciones especiales de El mundo ilustrado con gran cantidad de contenido en inglés, pero además las ediciones diarias de The Two Republics (1868-1900) o The Mexican Herald (1895-1915), asi como otras publicaciones de menor duración.

4 De hecho, las promocionadas por la revista corporativa Le béton armé, editada por la casa Hennebique en Paris, no lo fueron desde la prensa capitalina y el cemento empleado por los contratistas asociados a François Hennebique no fue de origen francés. Así puede apreciarse en los anuncios comerciales publicados en $\mathrm{El}$ imparcial, El mundo, El tiempo, The Mexican Herald, The Two Republics.

5 J. Figueroa Doménech se refiere a Tomas Carandente Tartaglio de la Fundición Artística ubicada en Tacubaya (Figueroa 1899: 96).

6 Inicialmente, la tienda era sólo una parte de la edificación, cuyo propietario, José de Teresa y Miranda, hacía promover principalmente su carácter empresarial: "Una gran parte de las oficinas está ya ocupada, y es halagador ver el movimiento de hombres de negocios, mensajeros y mozos que sin cesar van y vienen por las lujosas galerías del patio central, buscando a los negociantes y profesionales que acudieron los primeros a aprovecharse de las ventajas de este palacio del trabajo..." (S.A., El mundo ilustrado, 1898: 475). Las reformas posteriores fueron causadas por el predominio de la tienda departamental. En 1900 se anunciaba “...Robert y Cía., propietarios del establecimiento de ropa "La Valenciana", que hace poco fue destruido por el fuego, ha tomado en arrendamiento los grandes almacenes del Centro Mercantil..." (S.A., Diario del Hogar, 1900). La transformación definitiva del edificio en tienda ocurrió en 1916 (S.A., El nacional, 1916).

7 Habia modernos proyectos tras lenguajes clasicistas aun iniciado el siglo XX, como el 'edificio de Chicago', diseño del arquitecto Daniel Burnham, que en 1909 Harry G. Selfridge instalaba en Londres (Barnett 2013).

8 El edificio con fachada metálica de Hermann Boker en Mahattan fue construido en 1872 en el mismo entorno comercial donde más tarde se construyeron algunos de los primeros edificios con firma De Lemos \& Cordes. (King 1893: 902).

9 El trabajo de la sociedad De Lemos \& Cordes ha sido mencionado en guías de la arquitectura de Nueva York, así como de otras ciudades en la costa este de los Estados Unidos, pero no ha sido destacado en la historiografia de la arquitectura americana, aun cuando realizaron numerosos edificios comerciales con gran éxito.

10 La esencia y caracterización del rascacielos llegaría con las modificaciones en el código de construcción de Nueva York que permitió la construcción de porticados, los cuales hacía mucho tiempo se permitían en Chicago, asi como en lo precisado en The Real State Record and Builders Guide to New York City de 1898 (Evening Star 1905: 8).
11 Faltaban algunos años para que Louis Sullivan redactara los principios básicos para la construcción del rascacielos. Sus principios fueron, como es sabido, el resultado de la experiencia en el diseño de edificios cuya altura y funciones superaban los principios de la arquitectura hasta entonces tradicional. La tipificación teórica, que plasmaba en letras de molde lo hecho ya por más de diez años en Chicago, Buffalo o Nueva York, la redactaría Louis Sullivan para ser publicada en Lippincott's Magazine [Sullivan 1896].

12 La empresa se anunciaba en los apartados de Iron and Steel Roofing; Iron, artistic wrought, work; Iron beams, angles, channels and T. Iron, Ron buildings, fronts and roofs; Iron columns, girders, lintels and sills; Iron merchants; Irons roof mfrs.; Machinists tools and supplies; Malleable iron castings; Nail makers; Rolling mills; Steam, gas and water pipe and fittings (New York City record and building trades directory, 1892).

13 En Nueva York, la empresa había construido el Hotel Majestic en 1894, según proyecto del arquitecto Alfred Zucker, así como en 1898 el Hotel Royalton de la oficina Rossiter \& Wright. Entre los de oficinas destacan el edificio para R.G. Dun, proyectado hacia 1899 por los arquitectos George Edward Harding and William T. Gooch (The New York Times 1898). A estos se sumaria el Hayward Building (luego Kohl Building) en San Francisco, proyecto de los arquitectos George Percy \& Willis Polk en 1901. En Sudáfrica habian construido, a la fecha de su trabajo en México, el W.J.Jagger \& Co. Building, en Cape Town, según proyecto del arquitecto Anthony M. De Witt, reconocido por haber introducido el sistema porticado metálico norteamericano en aquel país hacia 1885 ("Anthony M. de Witt”. Artefacts). Pocos años más tarde, en 1893, realizarian el Garlick building, proyectado por Charles A.S. Feeman, quien era agente de la muy conocida fundición escocesa MacFarlane's ("Charles A.S. Feeman", Artefacts). Ya para terminar el siglo, en Johannesburgo, Milliken Bros. trabajaba en el Eckstein Building, encargado por Hermann Eckstein, nacido en Hohenheim cerca de Stuttgart.

14 Las reuniones del grupo de arquitectos se iniciaron en el invierno de 1896-1897, cuando en el edificio diseñado por Dwight H. Perkins se establecieron Robert C. Spencer, Frank Lloyd Wright y Myron Hunt. El edificio se convirtió en el eje de encuentros que incluyeron a Webster Tomlinson, Irving Pond and Allen Bartlitt Pond, Walter Burley Griffin, Birch Long y el propio Boari, quienes regularmente se reunían para discutir temas de interés en la arquitectura de su tiempo (Brooks 1963).

15 De hecho, la arquitectura de la Exposición de 1893 resulta fundamental para entender su propuesta para el Palacio de Bellas Artes de la Ciudad de México, la cual enviara desde su despacho en Chicago, así como otras de sus propuestas internacionales. Los documentos gráficos de proyectos de Boari, hoy en la Ryerson \& Burnham Archives: Archival Image Collection (The Art Institute of Chicago. Disponibles en http://digital-libraries.saic. $\mathrm{edu} / \mathrm{cdm} / \mathrm{search} /$ collection/mqc/searchterm/ 
Competition!boari/field/all!all/mode/all!all/conn/ and!and/order/title/ad/asc) son los originales publicados, junto a los trabajos de notables arquitectos del último lustro del siglo XIX, entre ellas, las primeras prarie houses de Frank Lloyd Wright, en los catálogos de las exposiciones anuales organizadas por el Chicago Architectural Club (Thirteenth Annual Exhibition of the Chicago Architectural Club. 1900. Chicago: The Art Institute. Disponible en https://archive.org/stream/4751664_1\#page/n1/ mode/2up, [3 de julio de 2019]).

16 En 1901 Milliken Brothers, con sede en 1a Independencia, se anunciaba en México bajo la categoria "structural steel" (The Massey-Gilbert Blue Book of Mexico 1901: 157).

17 Para ese momento, la aseguradora se había mudado de Refugio 15 a Lerdo 2 (S.A., El tiempo, 1888). Un par de años más tarde, su agente general para el Distrito Federal era Roberto Boker y Co., cuando todavia la arquitectura de De Lemos \& Cordes no representaba a la casa ferretera en la Ciudad de México (S.A., The Two Republics, 1890; S.A., El economista mexicano, 1890).

$18 \mathrm{El}$ proyecto estuvo a cargo de Charles W. Clinton y William Hamilton Russell. "Head Office, Company's Building". Museum of the City of New York. Disponible en https://collections.mcny.org/Collection/Head\%20Office,\%20Company's\%20Building-2F3XC5NP7KUD.html [3 de julio de 2019].

19 Las cariátides pueden observarse en la perspectiva del edificio firmada por De Lemos \& Cordes, así como en las fotos del edificio recién terminado. Fueron eliminadas con la fuerte intervención al edificio a cargo de Carlos Obregón Santacilia entre 1925 y 1927 (Obregón Santacilia 1952: 50).

20 En el edificio se instaló la oficina local de Milliken Brothers, así como Seckbach y Cía. y desde ahi ofrecería sus catálogos de elevadores para personas y cargas. Aviso comercial en El imparcial, agosto 21 de 1905, p. 4; aviso comercial en El tiempo, octubre 10 de 1907, p. 4.

\section{Bibliografia}

"Anthony M. DE WitT". s.f. Artefacts: The Built Environment of Southern Africa. Disponible en http://www.artefacts.co.za/main/Buildings/ archframes.php?archid=390 [3 de julio de 2019]

BARnett, Harold C. Abril de 2013. "Mr. Selfridge and Chicago: A Backstory, Building Chicago". Disponible en http://sites.roosevelt.edu/ hbarnett/2013/04/29/mr-selfridge-and-chicago-a-backstory/ [29 de junio de 2019]

BOARI, Adamo. 1898. "La arquitectura nacional". El mundo ilustrado, 7 de agosto, p. 103.

BRooKs, H. Allen. 1963. "Steinway Hall: Architects and dreams". Journal of the Society of Architectural Historians, vol. 22, núm. 3, pp. 171-175.

"Charles A.S. Feeman". s.f. Artefacts: The Built Environment of Southern Africa. Disponible en
http://www.artefacts.co.za/main/Buildings/ archframes.php?archid=541 [3 de julio de 2019]

Cody, Jeffrey. 2003. Exporting American Architecture, 1870-2000. Londres/Nueva York: Routledge.

Condello, Annette y C. Vernon. 2004, "Adamo Boari, Mexico City and Canberra". 11th Conference of the International Planning History Society (IPHS): Planning Models and the Culture of Cities. Barcelona. Disponible en http://www. etsav.upc.es/personals/iphs2004/eng/en-pap. htm [3 de julio de 2019]

DE la PEÑA, Sergio. 1999. La formación del capitalismo en México. Fondo de Cultura Económica.

S.A., Diario del Hogar. 1900. "Gacetilla: Los almacenes del Centro Mercantil", 11 de noviembre, p. 2.

S.A., El economista mexicano. 1890. La Mutua (aviso comercial), 18 de enero, p. 4.

"El edificio de La Mutua”. 1906. El arte y la ciencia, vol. VII, núm. 10, pp. 258-264.

S.A. El imparcial. 1900. "Inauguración de la Casa Boker", 3 de julio, p.1.

S.A. El imparcial. 1902a. "Las construcciones en la Ciudad de México", 25 de agosto, p. 1.

S.A. El imparcial. 1902b. "El nuevo edificio de correos", 14 de septiembre, p. 1.

S.A. El imparcial. 1904. "Edificio de 'La Mutua' Compañia de seguros sobre la vida, de Nueva York", 13 de marzo, p. 3.

S.A. El imparcial. 1905. "El edificio de correos", 9 de abril 9, p. 1.

S.A. El imparcial. 1906. "La nueva casa de correos", 17 de febrero, p. 1.

S.A. El imparcial. 1907. "Los cimientos del Banco Hipotecario", 21 de enero, p. 2.

S.A. El mundo ilustrado. 1898. "El Centro Mercantil", 25 de diciembre, p. 474-475.

S.A. El nacional. 1916. Anuncio comercial, 15 de septiembre, p. 2.

S.A. El popular. 1901. "Dirección General de Correos", 17 de junio, p. 1.

S.A. El tiempo. 1888. The Mutual Insurance Company (aviso comercial), 7 de diciembre, p. 1.

S.A. El tiempo. 1901. "El Teatro Nacional", 24 de enero, p. 2.

EvEning STAR. 1905. "Era of Skyscrapers", 24 de junio, p. 8. Chronicling America: Historic American Newspapers. Library of Congress. Disponible en http://chroniclingamerica.loc.gov/lccn/ sn83045462/1905-06-24/ed-1/seq-24/ [1 de julio de 2019]

Figueroa Doménech, J. 1899. Guía General Descriptiva de la República Mexicana, vol. 1. Ciudad de México: R. de S. N. Araluce.

Gamboa OJEda, Leticia. 2013. Un edificio francés en Puebla. Origen, usos e imágenes de una edificación centenaria. Ciudad de México: Conaculta.

Grutchfield, Walter. "Henry Heide", Fotos and Images [2009]. Disponible en http://www.waltergrutchfield.net/heide.htm [1 de julio de 2019]

Katzman, Israel. 1973. LA ARQUitectura DEL SIGLO EN MÉxico. México: Universidad Nacional Autónoma de México. 
KInG, Moses. 1893. King's Handbook of New York City. Boston: Moses King. Disponible en https://archive.org/details/kingshandbookofn00king_0/page/902 [1 de julio de 2019]

LangloIs, John. 2012. "On Beyond Holcombe: Eimer \& Amend", 1898 Revenues [24 de junio de 2012]. Disponible en http://1898revenues. blogspot.mx/2012/06/on-beyond-holcombe-eimer-amend.html [1 de julio de 2019]

Martínez Gutiérrez, Patricia. 2005. El Palacio de Hierro: arranque de la modernidad arquitectónica en la Ciudad de México. Ciudad de México: Universidad Nacional autónoma de México.

Miller, Tom. 2012. "The Lost Arion Society: Park Avenue and 59th Street", Daytonian in Manhat$\tan [20$ de agosto de 2012]. Disponible en http:// daytoninmanhattan.blogspot.mx/2012/08/thelost-arion-society-park-avenue-and.html [1 de julio de 2019]

Miller, Tom. 2012, "The 1888 Armeny Building: No. 90 Nassau Street”. Daytonian in Manhattan [21 de septiembre de 2012]. Disponible en http:// daytoninmanhattan.blogspot. $\mathrm{mx} / 2012 / 09 /$ the1888-armeny-building-no-90-nassau.html [1 de julio de 2019]

Miller, Tom. 2012. "The 1893 Fulton Building: No. 130 Fulton Street (87 Nassau)". Daytonian in Manhattan [17 de octubre de 2012]. Disponible en http://daytoninmanhattan.blogspot. $\mathrm{mx} / 2012 / 10 /$ the-1893-fulton-building-no-130fulton.html [1 de julio de 2019]

Milliken Brothers Catalogue. Second Export Edition. 1905. New York, 1905. Disponible en https:// archive.org/stream/thiscataloguecon00millrich\#page/n5/mode/2up [3 de julio de 2019]

NEW YoRK City RECORD AND BUILDing TRADES DIRECTORY, 1892. Nueva York: The New York City Record Publishing Co. Disponible en https://archive. org/details/newyorkcityreco1892p2newy [3 de julio de 2019]

NYC Landmarks Preservation Commission. 2005. Keuffel \& Esser Company Building. Disponible en http://s-media.nyc.gov/agencies/lpc/lp/2178. pdf [1 de julio de 2019]

NYC Landmarks Preservation Commission. 1989. La dies' Mile Designation Report, vol. 1. Disponible en http://home2.nyc.gov/html/lpc/downloads/ pdf/reports/LadiesMile_Vol1.pdf [1 de julio de 2019]

Obregón Santacilia, Carlos. 1952. Cincuenta años de arquitectura mexicana. México: Patria.

PECK, Ralph Brazelton. 1948. "History of building foundations in Chicago: a report of an investigation”. University of Illinois Bulletin, núm. 29, pp. 5-69. Disponible en https://www.ideals.illinois. edu/handle/2142/4215 [3 de julio de 2019]

RADFORD, Dennis. 1998. "The Early History of the Tall Building in the South African City". Construction History, 14, pp. 41-58. Disponible en http://www.jstor.org/stable/41601860 [3 de julio de 2019]

Rivas Mercado, Manuel.1900. "El desarrollo de la Arquitectura en Méjico", El arte y la ciencia, Vol. II, $n^{\circ}$ 9, 129-133.
Silva Contreras, Mónica. 2016. Arquitectura y concreto armado en México: La primera década del siglo XX y el sistema Hennebique. México: Universidad Iberoamericana.

Sullivan, Louis. 1896. "The Tall Office Building Artistically Considered". Lippincott's Magazine [marzo], 403-409. Disponible en https://archive.org/details/tallofficebuildi00sull/page/n3 [1 de julio de 2019]

St. Croix Architecture. "Building for Edwin C. Burt and Co. on Centre and Leonard Streets..." Disponible en http://www.stcroixarchitecture. $\mathrm{com} /$ products/building-for-edwin-c-burt-andco-on-centre-and-leonard-streets-new-york-ny1888-de-lemos-and-cordes [1 de julio de 2019]

St. Croix Architecture. "Store and Factory Building for Henry Heide, Esq on Hudson and Vandam Streets". Disponible en https://www. stcroixarchitecture.com/products/store-andfactory-building-for-henry-heide-esq-on-hudson-and-vandam-streets-new-york-ny-1897-delemos-cordes [1 de julio de 2019]

The Massey-Gilbert Blue Book of Mexico. A directory in English of Mexico City. 1901. México: The Massey-Gilbert Company.

S.A. The Mexican Herald. 1899. "Public voice: another defense of skyscrapers", 5 de enero, p. 5.

S.A. The Mexican Herald. 1901. "Important notice to architects", 9 de mayo, p. 1.

S.A. The Mexican Herald. 1903. "New building firm", 5 de mayo, p. 2.

S.A. The Mexican Herald. 1904. "Building of the Mutual Life Insurance Company of New York", 13 de marzo, p. 1.

S.A. The Mexican Herald. 1906. "Edward F. Milliken dead", 14 de noviembre, p. 12.

S.A. The Mexican Herald. 1907a. "Milliken Brothers Plants shut down", 6 de junio, p. 1.

S.A. The Mexican Herald. 1907b. "Milliken Bros. bankrupt", 14 de junio, p. 5 .

S.A. The Mexican Herald. 1907c. "Notes on the passing day", 20 de Agosto, p. 12.

S.A. The Mexican Herald. 1913. "Milliken Brothers to maintain office", 15 de mayo, p. 2.

The New York Times. 1907. "Milliken Brothers fail for $\$ 6,500,000 ", 11$ de junio, p. 1. Disponible en http://query.nytimes.com/gst/ abstract.html? res $=9 \mathrm{D} 00 \mathrm{E} 5 \mathrm{DA} 133 \mathrm{EE} 033 \mathrm{~A}$ 25752C1A9609C946697D6CF [3 de julio de 2019]

The New York Times. 1898. "The Dun Building", 15 de mayo, p. 20. Disponible en http://query. nytimes.com/gst/abstract.html?res=9E02E4DC1738E433A25756C1A9639C94699ED7CF [3 de julio de 2019]

The New York Times. 1909. "Theodore De Lemos, architect, is dead", 12 de abril, disponible en http://query.nytimes.com/gst/abstract.html?res=9E03E7D81731E733A25751C1A9629C 946897D6CF [7 de julio de 2019].

S.A. The Two Republics. 1886. The Mutual Insurance Company (aviso comercial), 27 de mayo, p. 1. 
S.A. The Two Republics. 1890. The Mutual Life Insurance Company (aviso comercial), 15 de enero, p. 1.

S.A. The Two Republics. 1899. "Heard in hotels", febrero 16, p. 5.

VASSALLO, Roberta. 2013. La arquitectura en hierro durante el porfiriato. Tesis para optar al Doctorado en Historia del Arte. Ciudad de México: Universidad Nacional Autónoma de México. 